\title{
Grammar and Hands: Manual Turn-Taking and Its Relationships to Verbal Turn-Taking in the Transfer of Objects
}

\author{
Barbara Fox ${ }^{1 *}$ and Trine Heinemann ${ }^{2}$ \\ ${ }^{1}$ Department of Linguistics, University of Colorado Boulder, Boulder, CO, United States, ${ }^{2}$ Self-employed, AErøskøbing, Denmark
}

OPEN ACCESS

Edited by:

Simona Pekarek Doehler,

Université de Neuchâtel, Switzerland

Reviewed by:

Elwys De Stefani,

KU Leuven, Belgium

Johannes Wagner,

University of Southern Denmark,

Denmark

*Correspondence:

Barbara Fox

barbara.fox@colorado.edu

Specialty section:

This article was submitted to

Language Sciences,

a section of the journal

Frontiers in Communication

Received: 31 January 2021

Accepted: 23 July 2021

Published: 11 August 2021

Citation:

Fox B and Heinemann T (2021) Grammar and Hands: Manual TurnTaking and Its Relationships to Verbal Turn-Taking in the Transfer of Objects.

Front. Commun. 6:661721.

doi: $10.3389 /$ fcomm.2021.661721
When customers bring a material item to a shop for repair, they must make the item and its troubles inspectable to the staff at the shop. This typically requires physical manipulation of the object by the customer. For their part, the staff person may then need to take the item into their own hands to further inspect it. A physical transfer of the object from customer to staff person may thus need to be accomplished. A practical problem that can arise in such transfers is this: who has the rights and responsibilities to touch and hold the object at any given time? In our data from a shoe repair shop, this practical problem is one of turn-taking of the participants' hands, and the participants exhibit a clear normative orientation to "one person touches at a time", with gaps and overlaps being common but brief. The parallels to verbal turn-taking are explored, as are the different affordances of each semiotic resource. The data are in American English.

Keywords: object transfer, turn taking, turn design, transition relevant place, manual transfer

\section{INTRODUCTION}

Many of our mundane everyday actions involve the transfer of a physical object from one person to the other, whether this be for the purpose of handing over a cup of coffee at the breakfast table, a set of car keys before setting out on a drive, money or a credit card when paying for a service or good at a shop, the remote control for the television, etc. Being such a mundane part of our life, object transfers usually happen unproblematically and take place largely unnoticed. This, however, is not to say that such transfers are unorganized or incidental. Rather, as we shall demonstrate in this paper, some types of object transfer appear to be systematically organized, so that the object is always and only held or touched by one person at a time, except for the millisecond of time during which the object is transferred from person to person. The specific context we are exploring for this is that of a North American shoe repair shop, in which customers regularly hand over items that need repairing to the staff. Figure 1 illustrates a number of such transfers at exactly the moment in which the object is transferred, where both customers and staff are touching the object.

The seemingly seamless transfer of an object from hand to hand is reminiscent of the observation made for the transfer of conversational turns-at-talk, made by Sacks et al. (1974). Noting that turn transfer is generally smooth, with gaps (where no people are talking) and overlaps (where more than one person talks at a time) occurring, but only briefly, Sacks et al. (1974) convincingly demonstrated that turn-taking for talk-in-interaction is systematically organized through a set of "rules" that apply to turn constructional units, so that participants in interaction at any given time are able to foreshadow when a turn-at-talk is complete, when a new turn-at-talk can or should be initiated, and 

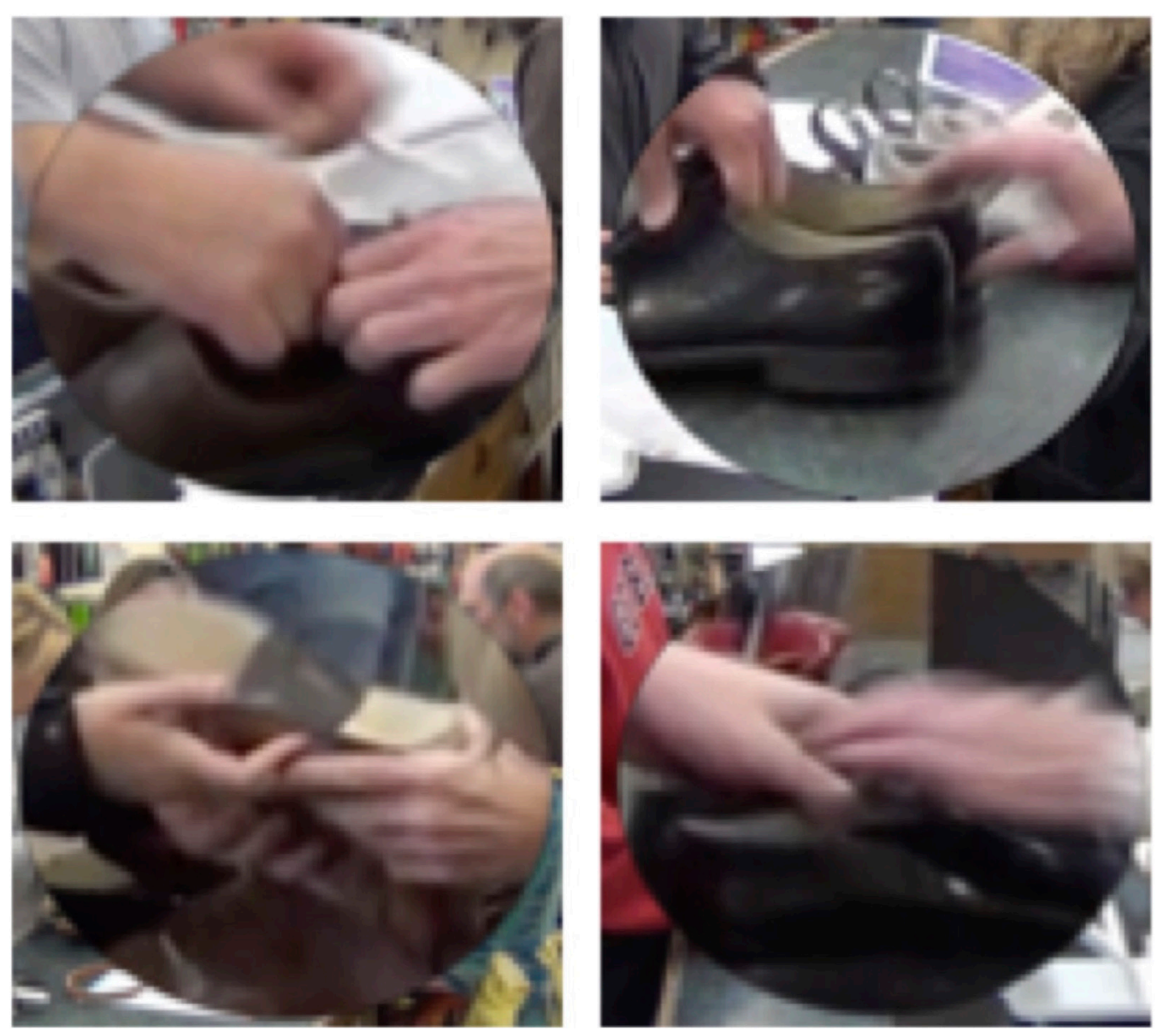

FIGURE 1 | The millisecond of an object transfer where the object is touched by both parties.

who can or should initiate that turn. The turn constructional units and the underlying turn-taking rules in combination thus serve as the explanation for the basic observation that when people engage in ordinary everyday talk, it is overwhelmingly the case that there is only one person talking at a time.

What we are similarly exploring in the current paper is the "systematics" for the organization of object transfer in the shoe repair shop. How is it that customer and staff manage to transfer an object brought in by the customer for repair in a manner that overwhelmingly means that the two touch the object simultaneously for only very short periods of time? How is it that gaps (where no one is holding or touching the object) and overlaps (where both participants are holding or touching the object) do occur, but then only briefly? And what occasions such occasional breaches of the systematics of object transfer and how are these breaches resolved by the participants? Our findings suggest, that in the shoe repair shop, the transfer of an object from customer to staff is tightly bound to the turn-taking system of talk and specifically to the production - by the customer - of a turnat-talk that can be understood as a request for service. Thus, we will show that by orienting to the ongoing production of the service request, customer and staff in most cases manage to accomplish a smooth transfer of the object on which the request is centered. Specifically, we will show that the manual transfer of an object in the shoe repair shop is coordinated to begin as the customer is coming to the end of their verbal request, syntactically, prosodically and pragmatically (Ford and Thompson, 1996); in other words, the embodied work of transferring the object from customer to staff is oriented to as due at what Sacks et al. (1974) termed a Transition Relevance Place (TRP), projected by the customer's formulation of their service request. At this place, we will show, a manual-visual inspection of the object by the staff has been made sequentially relevant, in order to determine whether the staff will grant or decline the request.

Our overall goals are, thus first, to document that object transfer is managed via a system that is parallel in many ways to the organization of verbal turn-taking. Secondly, we demonstrate that when troubles do occur in the otherwise smooth transfer of an object, these are resolved by the participants orienting to the same systematics of turn-taking that otherwise secure a smooth turn transfer. In order to highlight these parallels, we have chosen to adopt the terminology of the original turn-taking work and its subsequent development, thus using terms such as gaps and 
overlap for the transfer of objects in a similar fashion to how these terms are used for the transfer of turns at talk. We are of course well aware also of the differences between the two systems, in particular in terms of the different affordances lending themselves to the different media of interaction, and thus do not claim that the parallels we identify make the two systems identical despite the use of similar terminology. This and the issue of affordances are discussed in more detail throughout the paper and in particular in our discussion.

\section{BACKGROUND}

Though the interplay between language, the body and material objects has received some attention in recent conversation analytic literature on different commercial and professional settings (e.g. the edited volumes by Nevile et al. (2014), Day and Wagner (2019), Fox et al., (forth), as well as individual papers such as Streeck, 1996, Llewellyn, 2011, Heath, 2012, Mondada, 2019), studies that focus explicitly on how material objects are transferred between participants in interaction have only recently begun to receive attention. Moreover, these studies focus almost exclusively on the transfer of objects as a second pair part, i.e. on sequences in which some type of recruiting action has been initiated by one participant, either directly or indirectly, verbally or non-verbally, and a second participant offers assistance by proffering and handing over an object which will presumably meet the first participant's needs (e.g.Sanchez Svensson et al. (2007), Heath et al. (2018), Horlacher (2019), In general, across these studies, the focus is not so much on the object transfer itself, but on the recruitment sequence as a whole, and in particular on the intricate ways in which the participants manage to express and anticipate needs for assistance, and accommodate these. In their studies of the operation theatre, for instance, Sanchez Svensson et al. (2007), Heath et al. (2018) and Heath and Luff (2020) explore how nurses, surgeons, trainees, anesthesiologists and other medical professionals monitor each other's embodied conduct to anticipate when the passing of a medical tool or instrument is relevant, so that any accompanying talk in the form, for instance, of instructions or requests becomes unnecessary. Similar behavior has been observed in other professional settings, such as the hair salon (Horlacher, 2019), where apprentices likewise monitor the hair dresser's activities to determine when it is relevant to provide a portable mirror used for the customer to assess the outcome of the hairdresser's work. Studies by e.g. Rauniomaa and Keisanen (2012), Drew and Kendrick (2018), Kendrick (2021) and deSouza et al. (2021) that all focus on more everyday situations between relatives and friends similarly consider how the proffering and transfer of an object serves as a second pair part of a recruitment sequence. See also the much earlier and seminal work by Wootton (1991, 1994, 1997).

That object transfers are not exclusively used as a second pair pat of the recruitment sequence is illustrated in recent studies by e.g. Day and Wagner (2014), Tuncer and Haddington (2020) and Mondada and Sorjonen (forth), all of which focus more explicitly on the actual object transfers and how these may serve as a resource for displaying agency and involvement. With data collected from design workshops, Day and Wagner (2014) demonstrates how the material objects at the participants' disposal serve as "tools of talk", where the reaching for, taking, or holding on to an object can be used by participants to claim ownership not only of the object itself, but of the right to talk. Their findings moreover indicate a close interrelation between turn design and turn-taking on the one hand, and the transfer (and manipulation more generally) of material objects. The study of object transfers in a range of different contexts by Tuncer and Haddington (2020) further investigates the interrelation between the physical action of giving and taking an object on the one hand, and the verbal actions of requesting, offering and proffering on the other hand. They conclude that this interrelation and especially the way in which it is "played out" in a sequence of interaction makes for "meaningful resources for either participant to display agency in a joint course of action" (pp. 84). Similarly, Mondada \& Sorjonen's (forth) study of how merchandise is either placed and grasped, or given and taken, by customers and service providers in the context of convenience stores (so-called kiosks) illustrates that objects are transferred not just from the "assistant" or person offering assistance to the recruiter of assistance, but also in the other direction and as the embodiment of something other than a second, responsive action.

In the current study, object transfers similarly do not constitute the second pair part of a recruitment sequence in so far as it is in fact the recruiter (customer), who, upon delivery of their recruiting action or request, will proffer the object on which the request centers, to the respondent (service provider). In many ways, then, it seems that in this context the transfer of an object is in fact a constituency of the first pair part, the request for service, which then enables the service provider to provide a second pair part or response to the request. We thus build on the findings outlined above, to investigate in a systematic fashion, how turn design, turn-taking and the embodied action of transferring a material object across the counter in the shoe repair shop are closely interrelated, and specifically how the transfer of objects is closely coordinated with turn transition, in this specific context.

\section{DATA}

Our data for this study consists of video-recordings of service encounters in a shoe repair shop in a small town in North America, collected over the period from 2013-2015, with the written consent of the shop owners and implicit consent by the customers and staff. Though a shoe repair shop, the staff will attempt repair on almost any leather item, including shoes, boots, belts, and even baseball gloves and saddles. In addition, they will sometimes work on non-leather items, such as suitcases. The shop is owned and operated by a family, the current owner being the grandson of the founder; there are a few employees outside of the family who also work at the counter on occasion. Since there is no appropriate English term for the people who work at the shop, we have coined the term "shoetender," on the model of "bartender," to refer to them.

The video-recordings include instances in which customers bring an item in for repair, moments when they come to pick up 
their now-repaired items, and a few instances of customers coming in to browse for purchasable items such as insoles, laces and polish, or to inquire about the shop's services. For the purposes of the current study, we focus exclusively on the instances in which customers bring in an item for repair, so-called "drop-offs", of which we have for previous studies collated approximately 200 cases (see e.g. Fox and Heinemann 2016). As noted by Mondada \& Sorjonen (forth), there is a significant distinction between what they call "putting" and "giving" in the context of service encounters. In the shoe repair shop as well as in the kiosks they investigate, customers may on occasion simply deposit an object on the counter, leaving it entirely up to the service provider at which point in the interaction they would wish to pick up that object, either to enter the cost of the item in the till (in the context of the kiosk) or to inspect the item to determine the needed repair (in the context of the shoe shop). On other occasions, customers instead hold onto the object and pass it on to the service provider at what they deem to be an appropriate place in the interaction. As it is exactly this point of the interaction and its interrelationship with the physical transfer of the object that we are interested in here, the current study is further delimited in scope by examining only cases in which the item is 1) given by the customer into the hands of the shoetender, or 2) taken by the shoetender from the hands of the customer. In other words, we have excluded cases in which the customer has placed the item on the counter for the shoetender to take, and the shoetender picks it up from the counter. There are roughly 90 instances of the focal phenomenon, out of the total of about 200 drop-off cases we have examined.

Drop-off cases are organized around the same set of sequential relevancies and so run off in very similar ways, though with variation from case to case. Typically, we have found that a customer entering the shoe shop with an item that they are seeking a repair for will exchange greetings with the shoetender, approach the counter and produce a verbal service request as soon as they have established an interactional framework with a shoetender at the counter (Fox and Heinemann, 2020). On occasion, a few customers will engage in smalltalk before getting to the business at hand and occasionally the shoetender will produce an inquiry such as "how can I help you" to invite the customer to produce their service request. While producing the service requests ${ }^{1}$, customers will typically manipulate the item they have brought in for repair, thus both indicating manually what the problem is and making the problem visually accessible to the shoetender (Fox and Heinemann, 2015; Heinemann and Fox, 2019). Again typically, once the customer has reached the completion of their service request, the item will change hands, literally, and the

\footnotetext{
${ }^{1}$ Service requests come in a range of different syntactical formats, each produced in orientation to the individual contingencies and spatio-temporal circumstances of matters such as the item itself, the problem for which a solution is sought, the shoetender and customer's relative positioning in the shop and so on. In other work, we have described in detail how these various contingencies and circumstances are reflected in the linguistic variation of the verbal service request (Fox and Heinemann, 2016, 2017, 2021). For the current study, where we are concerned primarily with the projected transition relevance place of service requests more generally, we do not distinguish between the different syntactic formats for making service requests, except in our analysis of how the syntax of each format or case projects a particular grammatical transition point.
}

shoetender will inspect the item more closely, concluding from this inspection whether they will be able to solve the problem and repair the item to the customer's satisfaction, as well as what the cost of their potential solution will be. It is this transfer of the item, from customer to shoetender, that we are interested in exploring in the current paper. Extract (1) provides a first and very illustrative example of the pattern described above ${ }^{2}$ :

In this extract, the customer approaches the counter with a pair of Birkenstock sandals in her hands. After the greetings at lines 01-02, she begins her requesting utterance with what we call a preliminary statement (so:- (.) I:::, have (0.4) these,; Fox and Heinemann, 2020), which is timed to allow her to arrive at the counter (on these, line 04), before starting the request proper (see also Sorjonen and Raevaara, 2014). Having briefly placed the sandals on the counter upon arrival, the customer picks them up again and starts to flip them as she initiates the request proper, which is here formatted as a declarative of trouble (Fox and Heinemann, 2021): the soles are getting (0.8) pretty close to wearing thru- (0.2) t- (.) to the cork?.hh. By the end of getting, the soles are fully exposed, and the heels are pointing directly towards the shoetender and in the shoetender's line of vision. As the customer produces thru-, we see that the shoetender begins to move her hand to reach for the sandal (line 6). Interestingly, this is also the point at which the customer's declarative request could be at least syntactically and pragmatically complete, despite the truncated nature of through, the customer's utterance adequately describes the trouble with the sandals and as such allows the shoetender to determine - after an inspection - whether they are able to deliver the requested service. Prosodically, however, the customer's turn is not complete, and though the shoetender's arm is fully extended at $t$-, her hand has not yet reached the sandal. Moreover, while the customer initiates a self-repair (Schegloff, 2000) on this part of her utterance, the shoetender holds her hand in place, so that it is only when the customer's request comes to both syntactic, pragmatic and prosodic completion on cork, that the shoetender's hand arrives at the sandal. Notably, it is also only at this point that the customer lifts her gaze from the sandal and towards the shoetender, thus further indicating that a TRP has occurred and that the shoetender is being selected as next "speaker" (Kendon, 1967; Stivers and Rossano, 2010). In fact, on cork, it also seems that the customer very subtly moves the sandal towards the shoetender's hand, with this slight movement of "giving"3 (Mondada \& Sorjonen, forth) further indicating the reaching of a TRP and moreover projecting what the next relevant action would be (the shoetender's taking and inspecting the

\footnotetext{
${ }^{2}$ To best capture the details of both the verbal and the physical interaction for the current study, we present all cases discussed with a combination of transcription methods: Verbally produced data has been transcribed following Jefferson (2004) to capture best the exact timing, construction and production of the service request that is at the center of our focus here. To indicate how the customer's production of the service request relates to the transfer of the item, we include a graphic transcript (Laurier, 2014) below the Jeffersonian version.

${ }^{3}$ This giving movement may be afforded - or reflected - by the shape of the shoetender's hand as it approaches the sandal - it is palm up and open. The customer can thus easily move the sandal into the shoetender's open hand at the exact right time.
} 

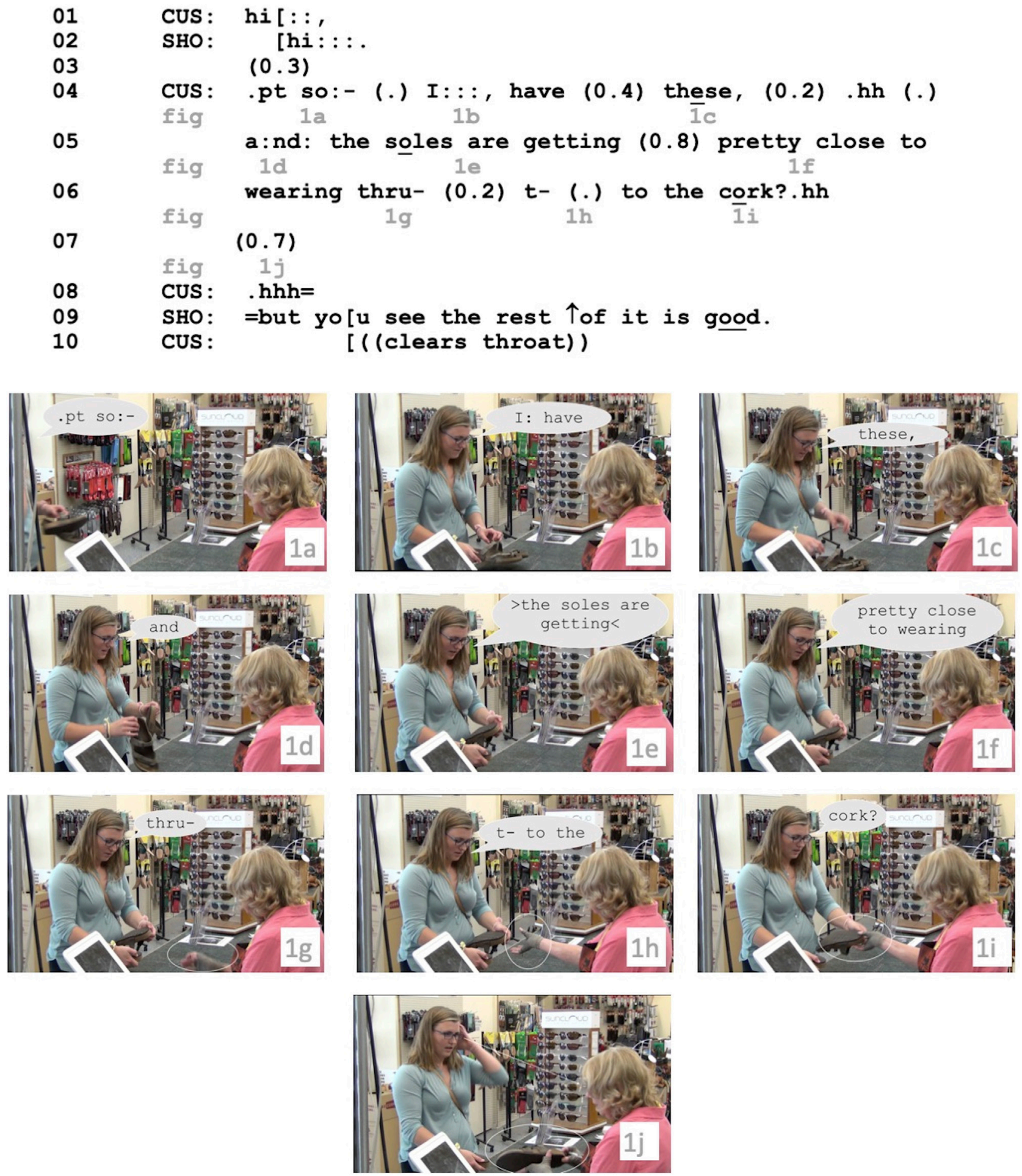

sandal). As soon as the sandal is thus placed in the shotender's hand, the customer releases her hold of that sandal (although she continues to hold the other one), and the transfer is complete.
Extract (1) above thus illustrates quite exquisitely how both shoetender and customer are orienting to the TRP of the turnat-talk and specifically of the customer's service request as 
being the exact moment at which a transfer of the repairable item could and should take place. The participants' orientation to accomplishing this at the exact moment at which the service request is complete, is so finely attuned to the linguistic production of the service request that we see the participants adjusting their manual movements in accordance not just with the syntax of the service request, but also the prosodic features of its delivery, as well as with any so-called disfluencies (hesitations and repair) that arise in the production. What we can gather from the extract and the finely coordinated actions that it attests is thus that the object which is transferred from customer to shoetender is touched jointly by both only for the very briefest moment possible, exactly because of their joint orientation to the TRP, so that the joint touching of the item occurs exactly at the TRP of the customer's service request (on the word cork) and is resolved immediately by the customer letting go.

We turn now to further analysis and discussion of how participants in the shoe repair shop orient to the relevance of making the transfer of an object as brief as possible and occurring at the exact point at which such a transfer has been made relevant. We begin by taking a further look at cases such as that of Extract (1) above, where transfer of the repairable item is smooth and quick (Smooth Transfers of Objects); we next consider cases that in various ways appear to go against this general pattern, either because the expediency of the transfer is challenged by a gap, in which neither participant touches the repairable item (Delayed Transfers of Objects), or because the transfer is challenged by an overlap, during which both participants hold on to the item (Overlapping Transfers of an Object). We conclude with a discussion of how the particular affordance of repairable objects and the fact that the transfer of these takes place in a different stream than the verbal interaction in various ways influence the overall impact and effect of breaches to the normative pattern of establishing a smooth transfer, with no gap and no overlap.

\section{Smooth Transfers of Objects}

In this section, we focus on object transfers that are accomplished smoothly and in orientation to the turn design and TRP of the ongoing co-occurring talk. We dwell on this topic a bit to establish that participants do, in fact, orient to the TRP as a place for making an object transfer, and closely coordinate both their verbal and embodied action to reach that place together. Thus, just as the norm for verbal turntaking as illustrated by Sacks et al. (1974) is that "one person talks at a time", we similarly find that the normative orientation of the participants involved in an object transfer is that "one person touches at a time," and to accomplish this the participants use the turn-taking system of talk as a scaffold. We saw a first case of this coordination in Extract (1) above. Extract (2) below provides another instance.

Here the customer comes into the shop with his repairable items in a plastic bag, which is a fairly common occurrence in the shoe repair shop. For customers who bring in their items in bags, part of their initial work is to bring the items out of the bag so that the items are available for demonstration and inspection as and when the service request is produced. Often, customers who are occupied with getting items out of a bag will produce some verbal components in orientation to the fact that an interaction has been started with the shoetender and a service request is relevant next; this can be for instance in the form of a preliminary statement, or as in the case of Extract (1) above, a general statement of the purpose of their visit, which seems to be what the customer in line 04 is beginning to produce with (>I'm here to see<) (. if:). This statement is, however, never completed, and we see further evidence of the customer "stalling" for time while getting his shoes out of the bag, first when in line 06 he starts another statement (See this is ), secondly when he produces a long $u$ in place of completing this second statement, and finally with the long silence of $1.4 \mathrm{~s}$ in line 07 , during which he finally manages to get the shoes out of the bag and onto the counter. Only once the shoes are visible and on the counter, does the customer start the request, here in the form of an inquiry as to the cost of what he wants done (>how much would it< cost to (0.2) jus:t stitch this up a little $b i t^{h}:$., line 08). This is hearably complete at the end of bit pragmatically the requested service has been explicated, syntactically the clause is complete and prosodically we hear a step down to low in the speaker's range, a feature often found at turn endings in American English. There is also a very strong release of the final consonant of bit, and releases are known to be ending-implicative in English (Local and Walker, 2012). As in Extract (1) above, we see the shoetender orienting to the potential turn completion and thus a possible TRP and Object Transfer Relevance Place (OTRP) by beginning to move his hand towards the item, just before the turn is complete, in this case on the last syllable and word of the turn, bit. The shoetender's hand arrives at the shoe at the same time that he verbally produces a shift implicative kay (Beach, 1993), further underscoring his understanding that the service request is complete and that the next relevant action is an inspection of the shoe. As soon as the shoetender's hand touches the shoe on kay the customer begins to retract his hand; during the micro pause in line 11 and certainly upon his production of the incremental better than of line 12 , the customer has released the shoe and moved his hand to the other shoe instead. This incremental better than produced by the customer in line 12 makes Extract (2) particularly interesting from the perspective of establishing the relationship between the construction of the verbal turn (or the service request) on the one hand, and the transfer of the item on the other hand. The increment better than clearly serves as a continuation of the customer's service request, retrospectively changing his requested service from "stitching up a little bit" to "stitching up a little bit better" or even "a little bit better than [it is now]". Nevertheless, because the customer's request was originally hearable as complete already at "little bit", it is this potential TRP that the shoetender aligns both his manual and verbal actions to; by moving his hand to and taking the shoe at the end of this part of the turn and subsequently producing a shift-implicative kay, he clearly demonstrates that he has monitored the customer's actions and in particular his verbal production to identify the first possible TRP, where also a transfer of the item (or an OTRP) is relevant. Furthermore, we see the customer orienting to and accepting the preference for a smooth transfer at a TRP by 


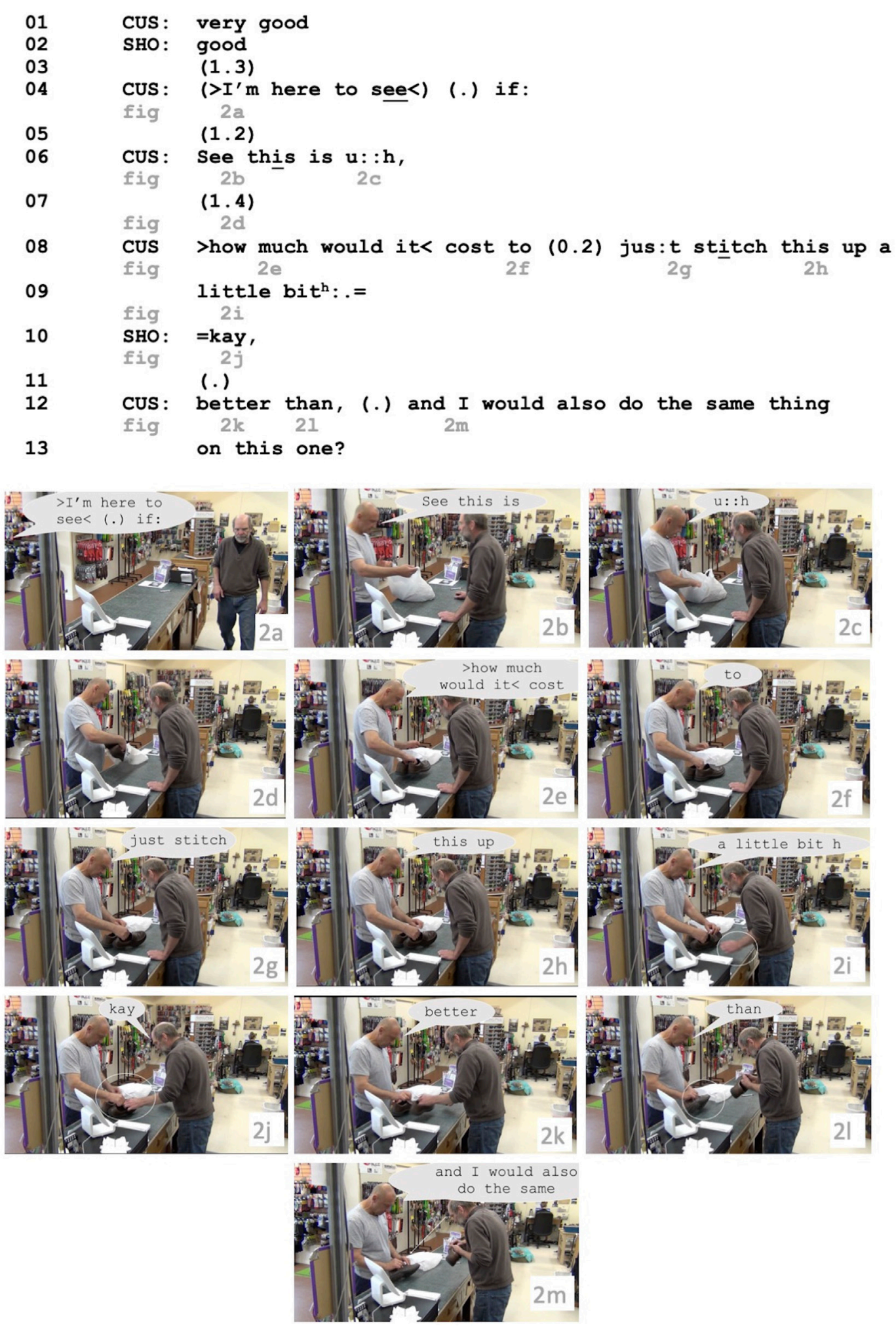

releasing his own grasp of the shoe as soon as the shoetender reaches for it.

In the next example, Extract (3), we see similar orientation to the relevance of object transfer at the TRP of a service request. In this case the customer has been waiting at the counter while the shoetender finished another transaction, so the shoes are ready and available as soon as the shoetender greets this new customer and thus lets her know of her availability. 


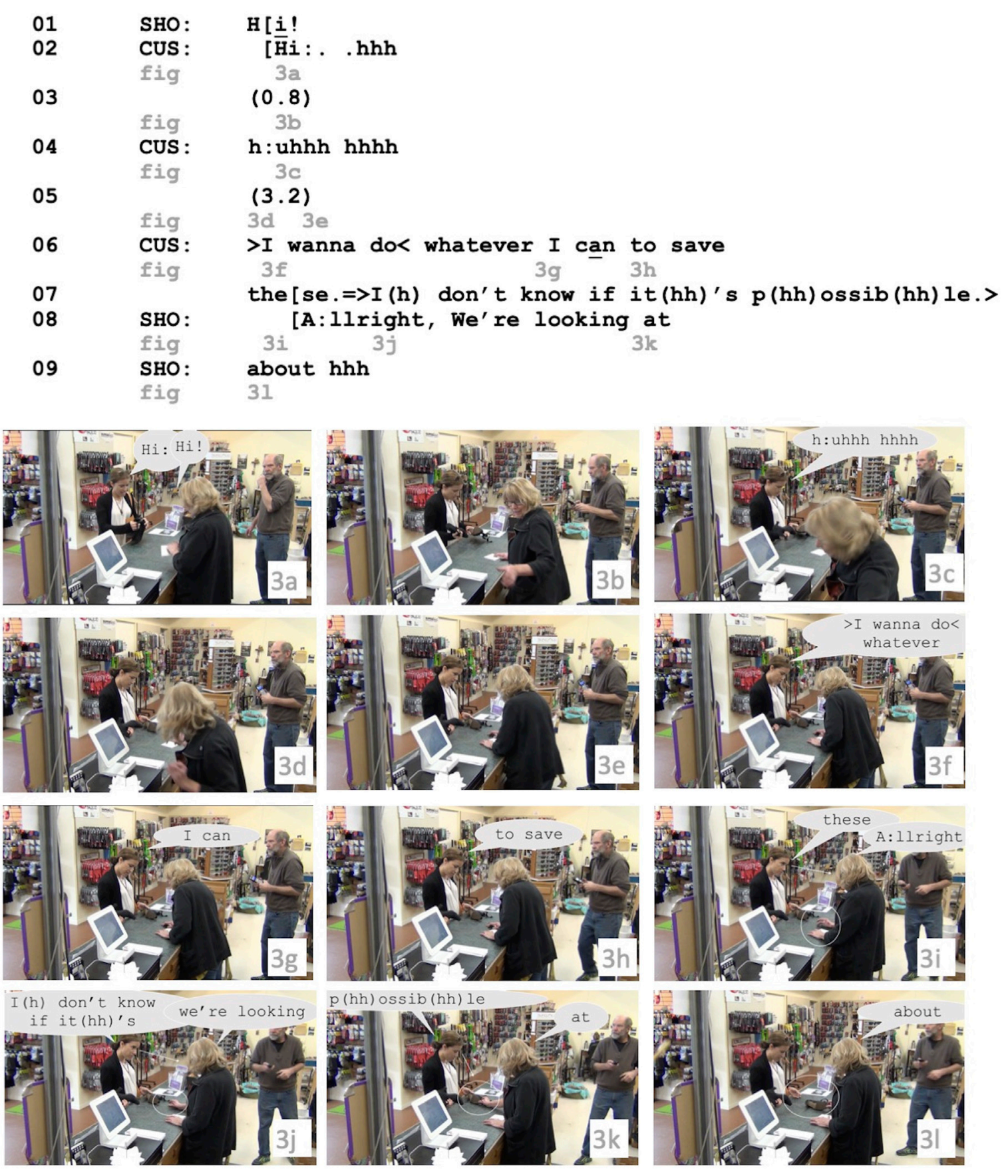

Having greeted the customer (lines 01-02) and thus initiated the service interaction, the shoetender torques her body and head away from the customer (and the shoes) immediately after the greeting, apparently to find a pen with which she can write down the customer's service request. Perhaps in orientation to this temporary disattention from the shoetender, the customer - as in Extract (2) above - seems to postpone the initiation of her request, though in this case not in orientation to the shoes being concealed in a bag but in orientation to them not being inspectable by the shoetender until she returns her attention in that direction. Immediately after their joint greeting, the customer takes a deep inbreath, as if gearing up to produce a turn (line 02). This inbreath is however first followed by a $0.8 \mathrm{~s}$ silence, during which the shoetender is leaning away from the counter, both head and torso in opposite direction, then - while the shoetender is still turning away from her - a deep out breath (line 04) and another even longer silence of $3.2 \mathrm{~s}$. Only at the point where the shoetender is back at the counter, leaning on and over it to look at the shoes, does the customer produce her service request in the form of the declarative statement $>I$ wanna do< 
whatever I can to save these. (lines 06-07). Such declarative statements are regularly used and responded to as requests for service in the shoe repair shop (Fox and Heinemann, 2021) and the customer's statement of line 06-07 is thus pragmatically, grammatically and prosodically complete on these. This is further underscored in this case - as in Extract (1) - by the customer lifting her gaze to look at the shoetender, thus indicating physically as well that a TRP has been reached and that the shoetender is the next selected speaker (Stivers and Rossano, 2010). As in our other cases so far we see the shoetender reacting to this possible TRP as well by moving her hand and starting to reach for the shoe, just before or around the last word or syllable of the turn, i.e. on these, thus treating the TRP also as an OTRP. Moreover, in this case - as in Extract (2) - the shoetender also verbally indicates a shift in activity, here by producing a:lright (line 08 ) before immediately beginning to answer the customer's request by service by inspecting the shoe and describing what needs doing to "save it" as per the customer's request.

In the three cases shown so far, we find - and hope to have shown - a clear pattern of the relationship between turn design and turn-taking, on the one hand, and the manual transfer of items on the other hand. Firstly, we see how customers design and produce their turn at talk and specifically their request for service in orientation to the shoetender's availability and possibility for attending to the object that is to be transferred for inspection. In other words, customers' service requests are clearly timed to come to a potential conclusion at a point where the shoetender is physically able to reach for the item and inspect it. Secondly, we see how shoetenders orient their physical actions and specifically the initiation of reaching for an item in relation to the on-going turn and service request produced by the customer, so that the hand movement required to grasp the item from the customer is initiated just before the pragmatic, prosodic and grammatical completion of the service request. Finally, we see that the customers orient to the end of their service request as the projectable point for transferring the object, leaving the shoetender to initiate the next relevant action, both by them regularly directing their gaze away from the object and towards the shoetender at turn completion (in Extract (1) and (3)), and - not least - by them relinquishing their hold on the object that is to be transferred as soon as the shoetender's hand has reached that object, sometimes even furthering the transfer by shifting the item slightly in their hands to make it more easily graspable for the shoetender. In these ways, we argue, we see the participants in these types of service encounters orienting to a direct relationship between the verbal turn-taking of the service request on the one hand and the manual transfer of the item on the other hand, and in doing so they also display or build up a preference for object transfer to take place as smoothly as possible, with no - or very little - overlap, and with no - or very little - delay, just as is the case for verbal turn-taking as described by Sacks et al. (1974).

In the following we will explore this pattern and our findings further by considering cases, firstly, where there is a delay in the transfer of objects in relation to the completion or reaching of a TRP, so that there is a gap of time during which neither the customer nor the shoetender touches the repairable item, and secondly, cases in which there is some overlap in the transfer of the item, i.e. where the time during which both customer and shoetender touch and/or hold the item is longer than what is required to simply move the item from hand to hand.

\section{Delayed Transfers of Objects}

Just as was shown in the seminal work in Sacks et al. (1974) for verbal turn-taking, the transfer of objects does not always happen according to the norm of "one person touches at a time”. For verbal turn-taking, Sacks, Schegloff \& Jefferson clearly demonstrated that though it is typically the case that turn-taking takes place with very little gap between two different speakers' turns, gaps of longer than a millisecond (or "beat") do occur fairly frequently. Occurrences such as these, however, can, according to Sacks, Schegloff \& Jefferson, be explained by interactional relevancies, and are typically accountable and accounted for in a manner that in fact underscores the systematicity and regularity of the turn-taking system. We find that gaps that pertain to the transfer of objects in the shoe repair shop are likewise accountable and explainable, so that when the transfer of an object between customer and shoetender is delayed and a gap occurs where no one touches the object, this is either because there is a potential interactional problem with the shoetender being able to accommodate the requested service (i.e. a potentially dispreferred response, a rejection of the request could be underway), or because there is a temporary physical problem with the transfer (i.e. something blocking the transfer on the counter or the shoetender's hands being occupied). Given that we see delays in transfers in these two contexts only, we can say that such delays happen only "for cause", and thus treat the norm as "no gap/no delay".

Extract (4) below is a first instance of a delay in the transfer of an item; here the delay appears to be occasioned by the fact that the shoetender cannot immediately grant the requested service.

In this case, the customer is waiting at the counter to be served; her item, a pair of boots, is already on the counter. Notice that she rests her hand on the counter and only reaches for the boots when the shoetender opens the encounter formally by producing a request solicitation (whata we got) in line 11. In response to this request solicitation, the customer not only grabs the boot, but also initiates her request for service, which in the extract is formulated as a need-request (see Fox and Heinemann, 2016), um, I need to get these taken i:n:. While producing this request, the customer continuously holds on to the boot, while running her hand upwards on its seam, presumably to demonstrate manually what she is requesting (e.g. Fox and Heinemann, 2015). The shoetender monitors these movements on the boot throughout the request, while simultaneously using her left hand to move an item sideways along the counter, as if clearing space on the counter for her subsequent grasping of the boot. Once the item has been moved, however, she returns her left hand to a resting position on the counter, giving no indication that she is preparing to reach for the boot in coordination with the customer's ongoing request production.

At the end of line 12, on i:n:, the customer has reached a projected and clearly identifiable TRP, both pragmatically, 


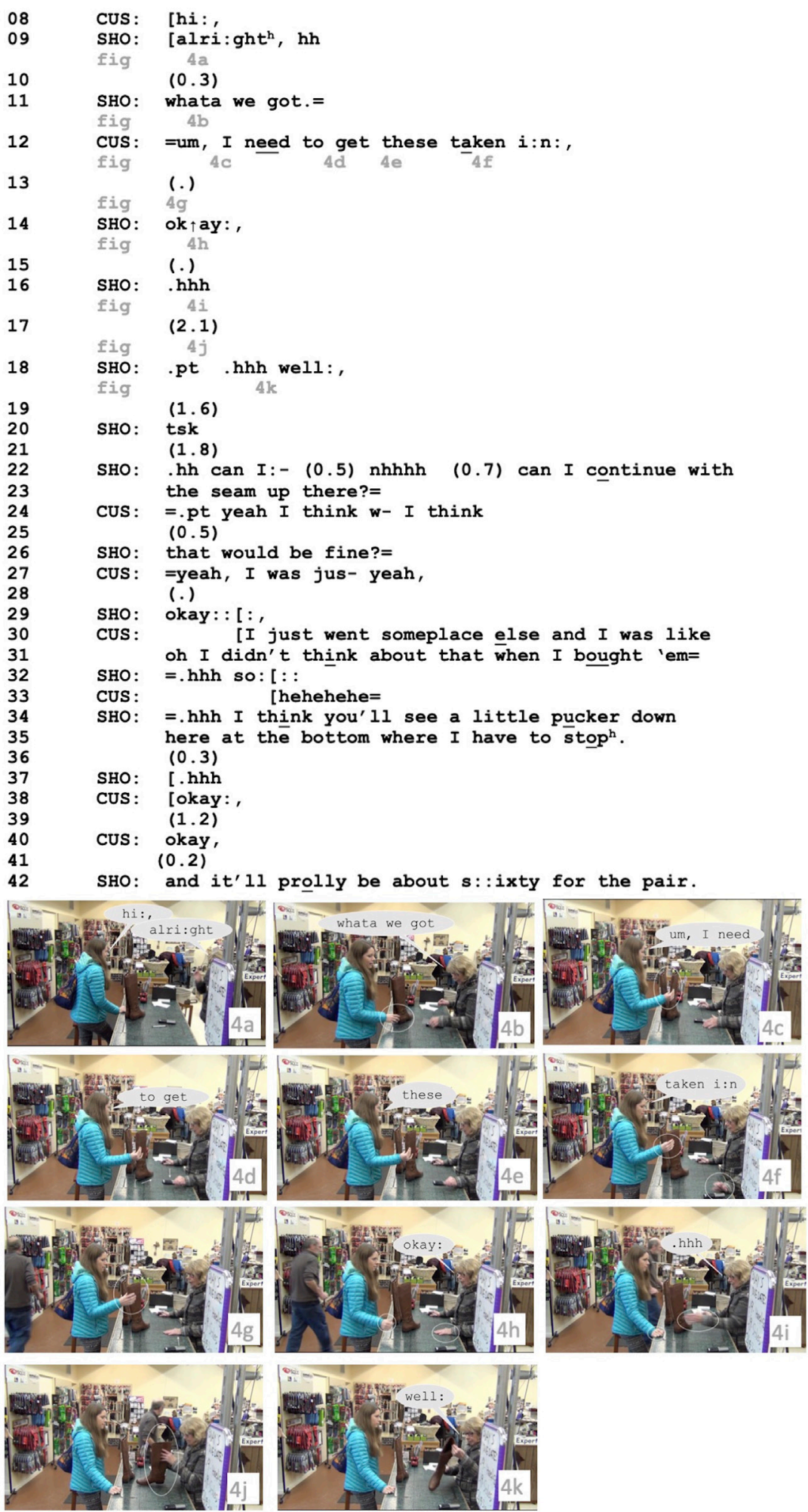

prosodically and grammatically, which is further underscored by her also directing her gaze up and away from the boots and towards the shoetender. At the same time, the customer begins to retract her hand from the boot, so that at the point where the shoetender begins to respond (verbally) to the request in line 14, neither the customer nor the shoetender are touching the boot. In other words, though a clear TRP and hence OTRP has been reached, and the requesting turn clearly completed, the object has 

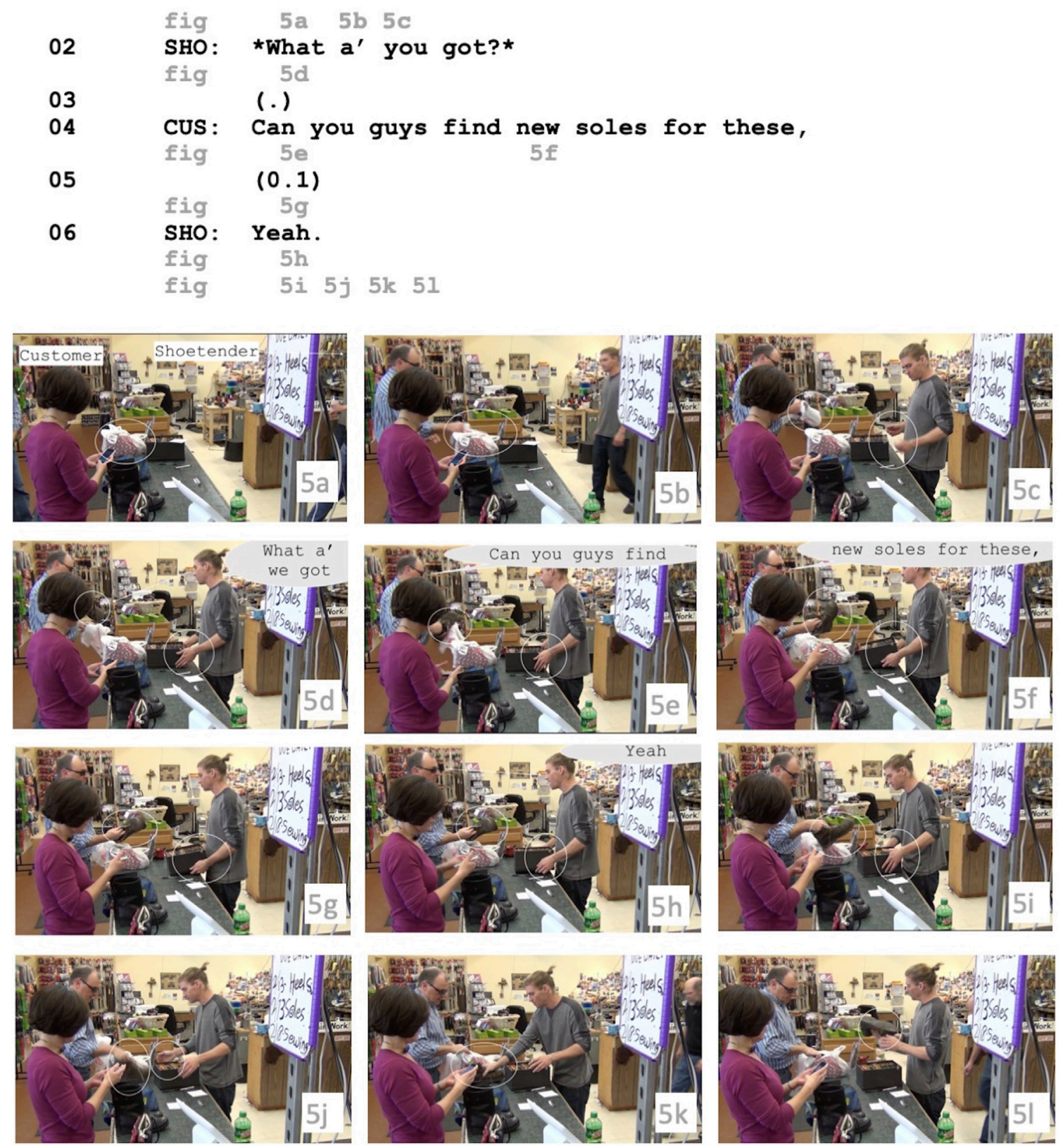

not been transferred between the customer and the shoetender, and in fact the latter has yet to make any manual indication that she intends to grasp and inspect the boot, her left hand still resting

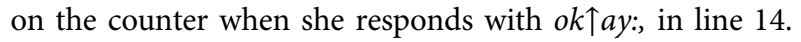

In total, a period of $1.1 \mathrm{~s}$ elapses between the time at which the customer releases the boot at the end of line 12 and before the shoetender does grab the boot during the silence of line 17 . We thus see a significant delay in the transfer of the item, or a significant gap of time during which no one touches the item, this despite the fact that the customer clearly projects a TRP both verbally, manually and through her shift of gaze. If we consider the ongoing and subsequent interaction, we begin to see what may occasion this delay or serve as a cause for a less-than-smooth transfer in this specific case. Firstly, the okay that the shoetender produces in line 14, as the first verbal response to the customer's request, does not share the characteristics of the other granting okays that we typically find in this context in the shoe repair shop (cf. Fox and Heinemann, 2016). The okay in line 14 is lengthened and produced with a rising-to-high pitch contour, indicating a less than favorable diagnosis of the situation, rather than it being a confirming or activity-shifting okay (cf Extract (2) as well as the alright of Extract (3) above). The sense that a potentially dispreferred answer to the customer's request is underway is further underscored by the slight delay before the okay is produced, and not least by the subsequent gaps in the production of a response (lines 15, 17, 19, 21) and the various perturbations and inbreaths produced by the shoetender in the intervening lines. At this point, though the shoetender has now 
reached for and grasped the boot, she thus continues to demonstrate potential problems with the service requested by the customer, by producing first a bilabial click and then a potential marker of dispreference, well: (see e.g. Ogden, 2013 on bilabial clicks and Davidson, 1984; Heritage, 2015 on well). Finally, when the shoetender does produce a more fully verbalized response in lines 22-23, this is not in the form of a granting as such, but in the form of a question that clarifies whether she can fix the problem in a particular way. That this may in fact not be a totally satisfying solution is further underscored when in lines 34-35 she describes a potentially objectional outcome of the repair, namely that the customer will see a pucker.

As the shoetender's verbal responses (and lack of same) in lines 13-23 above clearly demonstrate, the repair service that the customer requests in this extract is potentially problematic, and the shoetender is balancing on a line between presenting a potentially less than satisfying (and rather expensive) solution on the one hand and rejecting the requested service outright on the other hand. This, we believe, is what serves as the underlying cause for the delay in the physical transfer of the object from customer to shoetender, and specifically for the fact that the shoetender does not reach for the item in coordination with the projected completion of the customer's service request, as is otherwise done in cases such as Extracts (1)-(3) above. The observable and significant gap of transferring an object from customer to shoetender thus in this case clearly arises in parallel with a delay in the verbal granting of the request, as part of the larger multimodal package of treating the response as potentially dispreferred. In the context of a dispreferred (verbal) response, it also makes good sense for the shoetender to abstain from the otherwise normative orientation to securing a smooth transfer of the item, exactly because it seems that in the case where a smooth transfer does take place, the transfer also serves as a transition to the next logical activity in the request service sequence as a whole. That is to say, that by reaching for and grasping the item, the shoetender also physically marks that the responsibility for the item has shifted from the customer to the shop. By delaying this transfer and at the same time indicating potential problems verbally, the shoetender in Extract (4) manages to display that she is at least willing to investigate and suggest possible solutions to the customer's problem.

Extract (4) above thus clearly demonstrates that manual gaps or delays in the transfer of objects in the shoe repair shop occur, but also that they occur only for cause, which in turn underscores that there is indeed a normative orientation in this context towards accomplishing a smooth transfer. The cause, we find, is typically - as in Extract (4) - tied up with the potential dispreferred nature of the response, i.e. that the shoetender may not be able to grant the request, or that the requested service may not be possible or the outcome satisfactory. There is, however, a second, more practical circumstance that can serve as the reason for why an object is not transferred smoothly and immediately at the first possible TRP. Consider Extract (5) below. In this case, there appears to be no problem with the customer's request, nor with the shoetender granting it. However, due to the simple fact that the shoetender's hands are occupied with another object at the point where the customer's service request reaches a TRP, we find a gap of about $0.5 \mathrm{~s}$ where no one touches the item:
In this extract, the customer has come to the counter, but finding the shoetender occupied with serving another customer, he has placed his item, a pair of boots, on the counter and stepped back from the counter. Each of the boots is wrapped in a plastic bag, and as soon as the customer sees evidence of another shoetender approaching the counter, he steps forward, lifts one of the boots and begins to unwrap it, thus preparing himself for making the boot visually available for the shoetender who is about to attend him (see pictures below).

Worth emphasizing for this extract is how well the participants coordinate their actions in relation to each other, despite the occurrence of a gap or delay in the transfer of the object. Firstly, as noted above, the customer moves directly to the wrapped boots as soon as he recognizes that he is about to be served, and begins to unwrap the first boot as the shoetender is still approaching the counter. Secondly, the shoetender produces a request soliciting what a' you got (line 02 ) at the exact point at which the first boot is unwrapped and the customer responds immediately with the service request Can you guys find new soles for these (line 04). As in our other cases above, we here have a clearly projectable conclusion to the request on these, where the request is hearable complete, both prosodically, pragmatically and grammatically. We also see, as in Extracts (1) and (3) above, that the customer underscores the potential TRP and the manual relevance of this by shifting his gaze to the shoetender, and moreover pushing the boot he is holding up in the air slightly further towards the shoetender. However, despite the clearly recognizable and projectable TRP, the shoetender does not grasp the boot at this point, nor does he even make any movement of his hands towards it. He does, however, confirm and grant the request, both physically by nodding (line 05) and verbally by responding with Yeah (line 06). In contrast to Extract (4) above, the shoetender's verbal response to the request is not delayed, nor is it hedged in any way, and we also subsequently find no evidence in his behavior that the request is potentially problematic or that the solution that can be offered will be less than satisfactory. Instead, we see that the main reason for the shoetender not reaching for the boot at the TRP is that his hands are preoccupied with shifting a box and some papers that have been placed on his side of the counter. This shifting of items has been ongoing since he reached the counter and solicited the customer to begin his request, but with very little extra space on the counter and with another shoetender and customer occupying part of the counter, the shift ends up being unsuccessful in the sense that the shoetender does not manage to free his hands in time for the projected TRP. Interestingly, we see still in this case how both participants orient to the normative expectations of the transfer of the object taking place at the TRP and taking place smoothly, with both of them adjusting their movements to accommodate the circumstances: The customer, who has shifted the boot slightly forward towards the shoetender, holds the boot in this position for a beat, but then, upon hearing the confirming Yeah in line 06, begins to lower the boot, eventually placing it on the counter instead of handing it over to the shoetender. The shoetender, in turn, appears to abandon his shifting of the box and now times his movement of his right hand so that by the time the boot hits the counter he is already 
reaching for it, thus minimizing the gap as much as possible, so that it is only for a $0.5 \mathrm{~s}$ period that neither the customer nor the shoetender is touching the boot. Having grasped the boot, the shoetender then lifts it to his side of the counter and inspects it, thus proceeding with fulfilling the request in the normative manner and shifting to the next relevant activity, without further glitches.

As exemplified by Extracts (4) and (5) above, we do find examples in our data where at first glance it seems that the general norm of performing a smooth transfer from customer to shoetender of the item at the TRP of the service request is not maintained. As is the case for the turn-taking system of verbal turns described by Sacks, Schegloff and Jefferson, however, we can determine that the delays that may occur in transferring the item, with a resulting gap during which neither participant touches the item that is to be transferred, are for cause, i.e. are occasioned either by a physical obstruction that results in the shoetender not being ready (having his hands free) to reach for the item at the right point in time, or by a problem of preference, i.e. where the requested service cannot be immediately granted by the shoetender. From the extracts above we can also see that such gaps, though they do occur (if rarely), are furthermore minimized, spanning over a period of between $0.5-1.0 \mathrm{~s}$ roughly, and that the participants work to minimize this gap. Thus, we see that even when the norm for performing a smooth transfer is breached, the participants through their remedial actions clearly orient to this normative pattern as one that is relevant for them. In the following section, we consider other cases in which this normative pattern is breached, but here by the participants being in overlap with one another in terms of them both holding on to or touching the item, instead of performing a smooth and immediate transfer at the TRP of the service request. Again, we shall demonstrate that such overlaps occur for cause and that the participants orient towards resolving such overlaps as quickly and as smoothly as possible, thus further orienting to the otherwise normative pattern of accomplishing a smooth object transfer.

\section{Overlapping Transfers of an Object}

For verbal turns at talk, Sacks, Schegloff and Jefferson (1974) clearly established that overlap, during which more than one person speaks at a time, occurs, but also that it occurs systematically, i.e. around potential TRPs and for reasons that can be explained and demonstrated. Jefferson's (1984) work on overlap further detailed the systematicity of overlap, demonstrating that this may occur because there is some uncertainty around the projection of a relevant TRP, for instance because the current speaker has problems formulating their turn, continues their turn after an otherwise projected TRP and so on. Not surprisingly, perhaps, we can similarly demonstrate that the manual overlaps in our data, where two participants are holding on to the item at the same time, without a smooth and immediate transfer taking place, similarly occur for cause, and specifically for reasons of turn design and projectability of the TRP. In keeping with Jefferson's approach, we focus here not on classifying and categorizing types of overlap as much as on describing how these patterns of overlap arise. Extract (6) below provides a first instance of - in this case very brief-overlap, which is akin to Jefferson's (1984) "progressional" overlap, i.e. where the current speaker on the way to the projected TRP encounters problems with the formulation of her turn, so that the reaching of the TRP ends up being "delayed" compared to its projection.

In this case, the customer is waiting at some distance from the counter, while another customer is being served. Her repairable items, a pair of boots, are in a plastic bag, and as soon as a second shoetender indicates his availability by greeting her (line 01 ), she begins to move towards the counter, producing the preliminary statement I don't know if you can help me or not, but I: (0.5) (got) these boots: (lines 03-04). As is typically the case, this preliminary statement is perfectly produced in relation to making the repairable item available and visible to the shoetender before the request proper is uttered. In this case, the request is in the form of a declarative of trouble (Fox and Heinemann, 2021), the basic message of which is that the zipper on one of the boots is broken in some way. The customer initiates the declarative of trouble in line 05 , where the boots are out of the bag and being presented, and we can see that also the shoetender is orienting to this being the request proper, as he directs his gaze to the customer and the boots, whereas he was previously also monitoring the encounter going on to his side, between the other shoetender and her customer. It is evident from the start, however, that the customer has some problem formulating her problem, perhaps because she does not know exactly how to describe what is wrong with the zipper: she initiates her declarative of trouble with a hesitation marker $u$ : $m$, then a pause of $0.4 \mathrm{~s}$, before identifying the part of the boot that has the problem, one of the zippers: (line 05). At this point, it can be easily argued that a TRP for the service request is projectable, given that all that would be needed to complete the request pragmatically, grammatically and prosodically would be the production of a copula and adjective, such as "is broken". Indeed, we see the shoetender orienting to a projected TRP at this point, as he soon after begins to lift his left hand and move it towards the item. We have seen this pattern before, in which shoetenders initiate their grasping of the item just before a TRP had been reached, so that their hand can in principle be at the item at the TRP. In this case, however, the customer appears to have continued problems formulating her problem, and instead of completing her turn and request with the projected copula and adjective, she begins what appears to be a main clause. This too, she breaks off, and after another short pause of $0.4 \mathrm{~s}$ does another restart with $I$ :. At this point, however, the shoetender's hand has reached the boot and he now furthermore produces a collaborative completion (Lerner, 2004) of the customer's utterance, thus formulating the problem for her (It's bungled) and consequently also completing her request (see Fox and Heinemann, 2019 for other ways in which shoetenders may "telescope" request sequences to their conclusion when customers appear to have trouble formulating their request). The customer, in turn, confirms the shoetender's identification of the problem with yeah in line 08 , at the same time letting go of the boot and directing her gaze towards the shoetender, thus further confirming that the service request is now complete. 


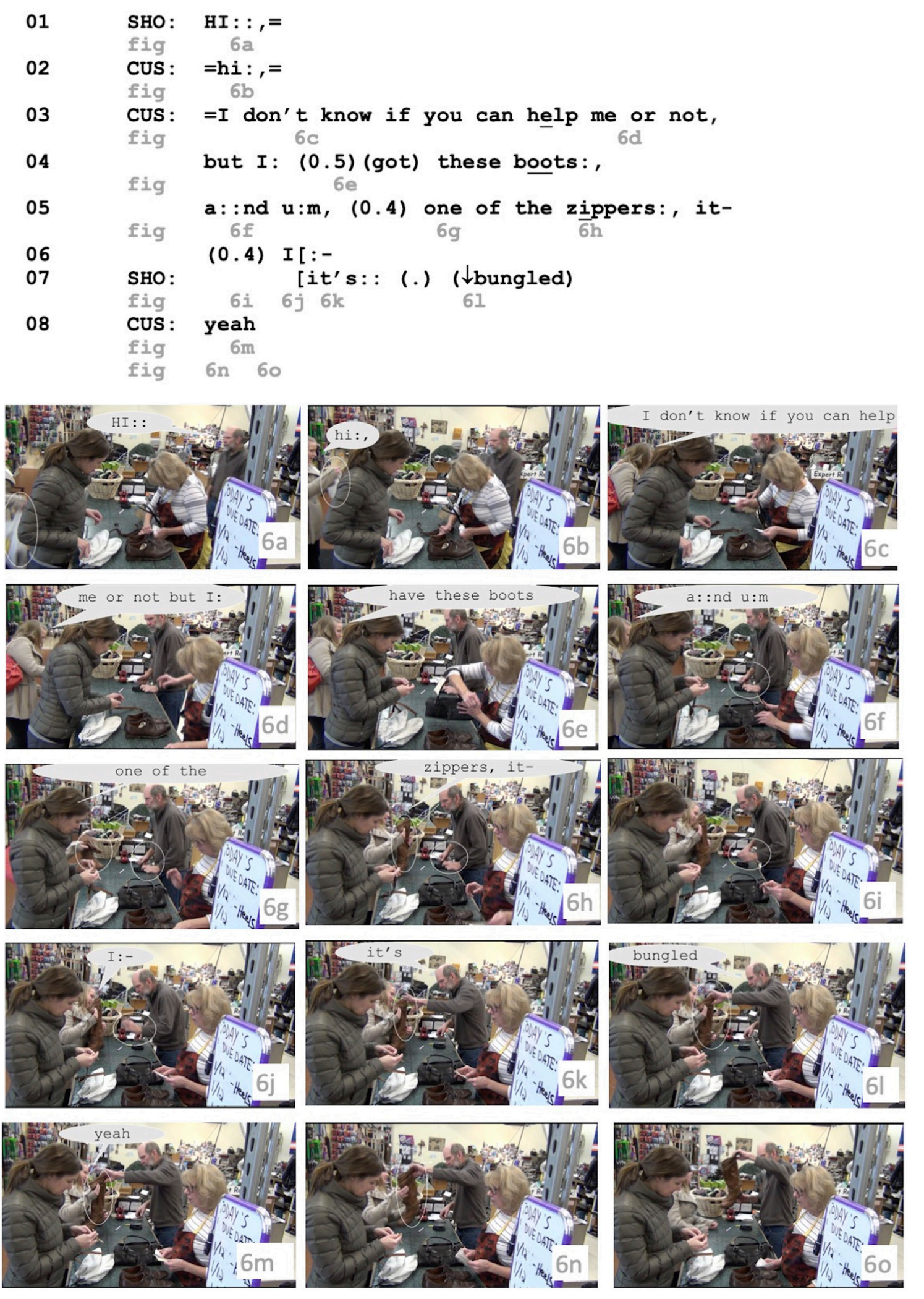

As was the case for the gaps discussed above, the period of time during which both participants in this extract hold on to the boot is brief, at around $0.4 \mathrm{~s}$. The overlap in touching is nevertheless tangible, more so perhaps because the shoetender has to almost lean over the counter to grab the shaft of the boot, holding it at a somewhat awkward angle at the top, to more or less drag it up and 
out of the customer's hand. This is accentuated further by the customer in turn letting her hand follow the boot being moved, so that when she does release it, she does so much closer to the middle of the counter than where she was holding it originally. It is clear, then, that in this case there is an overlap, so that the transfer of the item is not as smooth as in other cases; but it should also be clear that this overlap is very much for cause, and specifically because the customer had trouble completing her service request at the projected TRP, so that the shoetender ended up coming in a little early with his hand, with the resulting overlap occurring. It should also, moreover, be quite clear from the extract above that both the shoetender and the customer work to resolve this overlap, the shoetender by verbally completing the request on behalf of the customer, and the customer by confirming this completion and releasing the boot into the hands of the shoetender. As in the cases where we find a delay in the transfer of the object, in this case of overlap, we thus again see how the participants clearly orient to the normative pattern of accomplishing a smooth object transfer at a TRP in their quick and successful attempts at resolving the overlap.

In the previous section, we saw how relevancies other than turn-taking and turn-design may affect the degree to which the transfer of an item runs off smoothly or not; in the case of gaps in which none of the participants touches the item, for instance, we saw that if a dispreferred answer to the request is potentially in the frame, the shoetender may not reach for the item at or just before the projected TRP, with a gap occurring as a result of this. Similarly, we see in the following case, Extract (7), how a problematic answer to a customer's service request (or parts of it) may seemingly cause the shoetender to grasp for the item before a fully projected TRP, with a resulting overlap to follow, where both participants hold on to the item. As was the case for the extract above, however, we also see that the participants orient towards resolving such overlaps as smooth and as fast as possible, in orientation to the normative pattern of "no gap, no overlap":

Here, the customer has been waiting at the counter, shoes placed in front of him. As soon as the shoetender greets him and thus makes herself available, he picks up the shoes, and while the shoetender is still approaching the counter but clearly directing her gaze towards the shoes, he initiates his service request in line 05 , here in the form of a wonder-request (Fox and Heinemann, 2016) $\uparrow$ wondering if there's anything you can do. Around the customer's production of anything, the shoetender has reached the counter and begins to lean over the counter to closely inspect the shoes and monitor the customer's manual demonstrations of the problem for which he is seeking help. Grammatically and pragmatically, the customer's request could be hearably complete at scratch, but the slight rising prosody of the turn so far is akin to a list-construction (Jefferson, 1991), which indicates that a TRP has not been reached. Indeed, we see that the customer continues and in fact seems to be listing jobs that he would like the shoetender to perform on his shoes, i.e. fixing the scratch (line 06), scuff marks (line 07) and creases (line 08), even ending his list with a generic all that stuff, which is also a common trait of lists. Verbally, the shoetender does appear to understand that the customer's turn is not complete at scratch, as she notably does not respond to the request until after the completion of the full list, in line 09. Manually, however, she appears to override the customer's turn by reaching out her right hand, palm upwards, on the customer's beginning of the second part of his list, on and in line 06 . Her movement and hand gesture are very obvious, as they give the impression of the shoetender scooping up the shoe from within the customer's hand. This obviousness is further underscored when she subsequently places her left hand on top of the same shoe, as if to drag the shoe out of the hand of the customer, who is still holding on to it. The result, in any case, is that both participants hold on to the shoe for a period of approximately $0.8 \mathrm{~s}$, after which the customer relinquishes it. In this case - as in Extract (6) - this is due to the shoetender reaching for and grabbing the item before a TRP has been reached, but the reason for the shoetender's actions differs between the two cases. Whereas in Extract (6) it seemed that the shoetender's initiation of the manual transfer of the item before a TRP was part of an overall strategy for telescoping the sequence forward, and in that assisting the customer with formulating her request, in Extract (7) we see that the reason for the shoetender's manual interjection is the possibility of a dispreferred answer to the customer's request, on the grounds that the material of his item, patent leather, makes it hard to provide an acceptable result of the repair (lines 09-10, cf. similar dispreference oriented to in Extract (4) above where the result was a delayed transfer).

Manual overlaps during which both shoetender and customer hold on to the item that is to be transferred for even longer periods of time can also be found in instances in which there is some doubt or disagreement as to whether a service request has been produced, i.e. where the customer has produced a turn at talk that is complete, grammatically and prosodically, but has not - in their own understanding at least - produced a recognizable service request that specifies all their specific problems. We find one such instance in Extract (8) below, which evolves into a period of close to a minute during which the shoetender has grasped the item and is ready to inspect it, but where the customer is not relinquishing the item due to having more to say about the repair. The length of the manual overlap is clearly obvious, but again we can find the cause of the overlap in the turn design of the ongoing talk and also see clear evidence that the participants orient towards resolving this break from the normative pattern of a smooth transfer:

In this case, the customer has been waiting at the counter for an available shoetender, shoes on the counter, and as soon as one shoetender greets her, she initiates a request (line 02 ), which after some hesitations becomes fully fledged in line 05 . The format of the request is ambiguous as to whether it is a request proper, or a preliminary statement, but there are no contextual circumstances that makes relevant the production of a preliminary statement here, as the shoetender is at the counter and fully attentive from the beginning of the customer's turn, just as the shoes are visible (not concealed) and on the counter, with the customer being fully able to demonstrate her problem manually while producing the request. In fact, it seems that the reason for the formulation of the request as somewhat ambiguous in this case is due more to the fact that the customer is a returning customer, who has already discussed the repair she wants with another shoetender, a week ago (I came in and showed these to him, line 05). Presumably, the customer here wishes to formulate her request in a manner that 


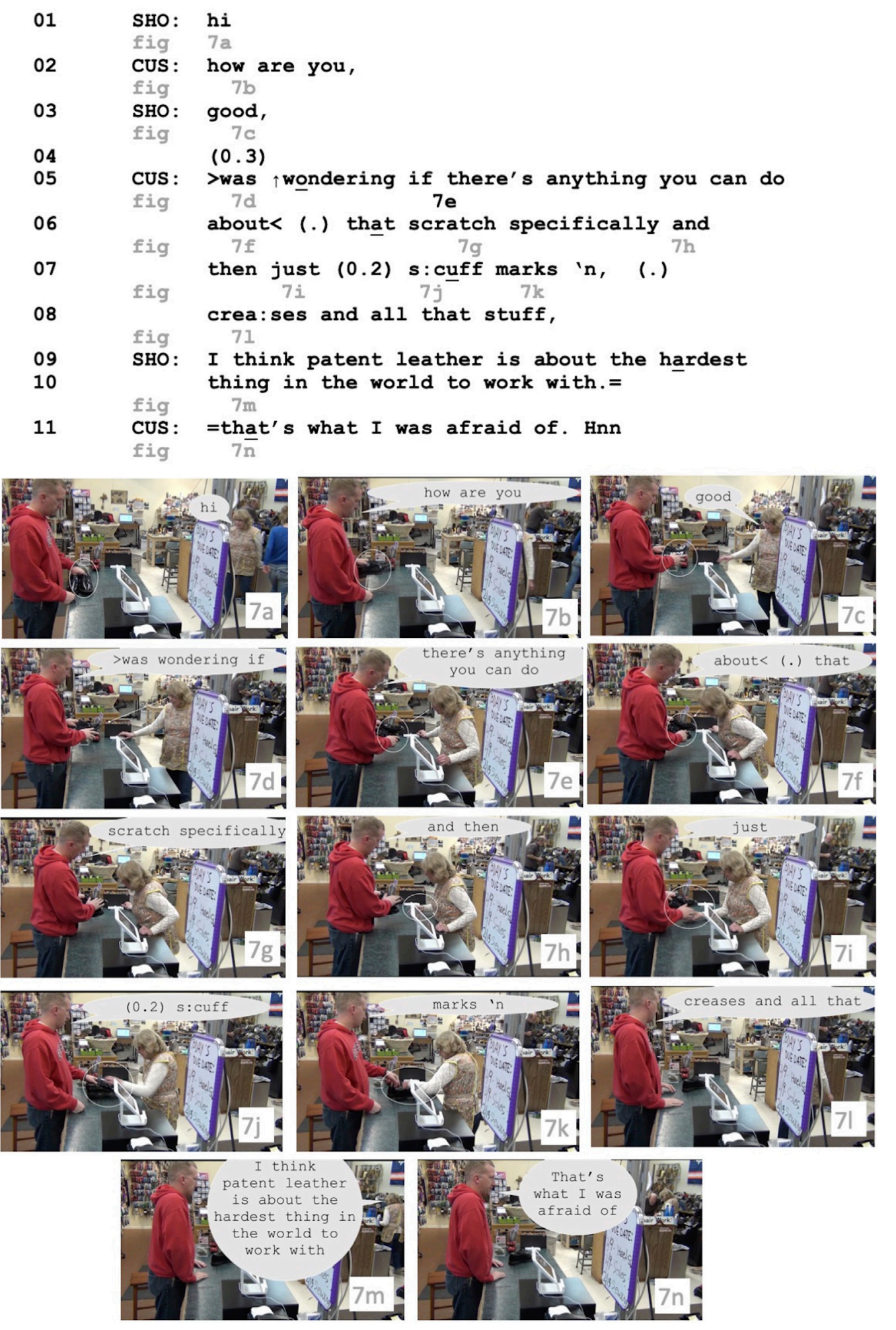

ensures that she is not offered a different solution to her problem than the one already discussed with a different shoetender the week before, by making it quite clear to the current shoetender that some particular repair has already been settled. From the shoetender's perspective, this can quite easily be interpreted as the request already having been completed (though 1 week before), and this especially at the point at which the customer has stated the repairable that seam at line 07 , at which the customer's turn at talk is 


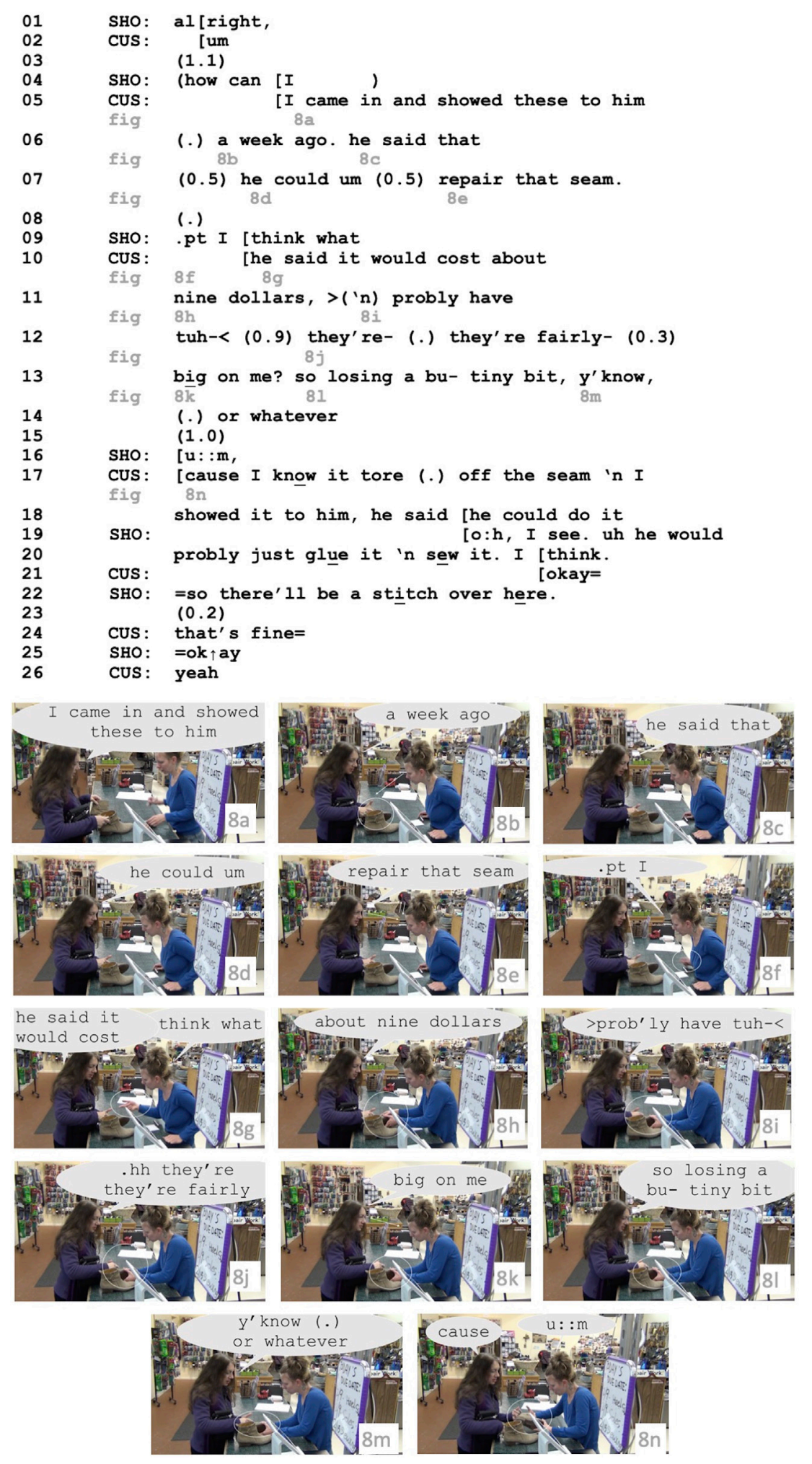

furthermore both grammatically and prosodically complete. To further accentuate this interpretation, the customer directs her gaze at the shoetender on seam, just as we saw other customers doing at the TRP of their service request. That the shoetender has interpreted that the customer has reached the TRP of her service request is in any case quite evident, as she begins to respond verbally (line 09) and moreover lifts her right hand from the counter and moves it towards the shoes. As it turns out, however, the customer is not quite finished relaying her earlier agreement with another shoetender to the current shoetender, so she continues talking, now explaining that she was also told the cost 

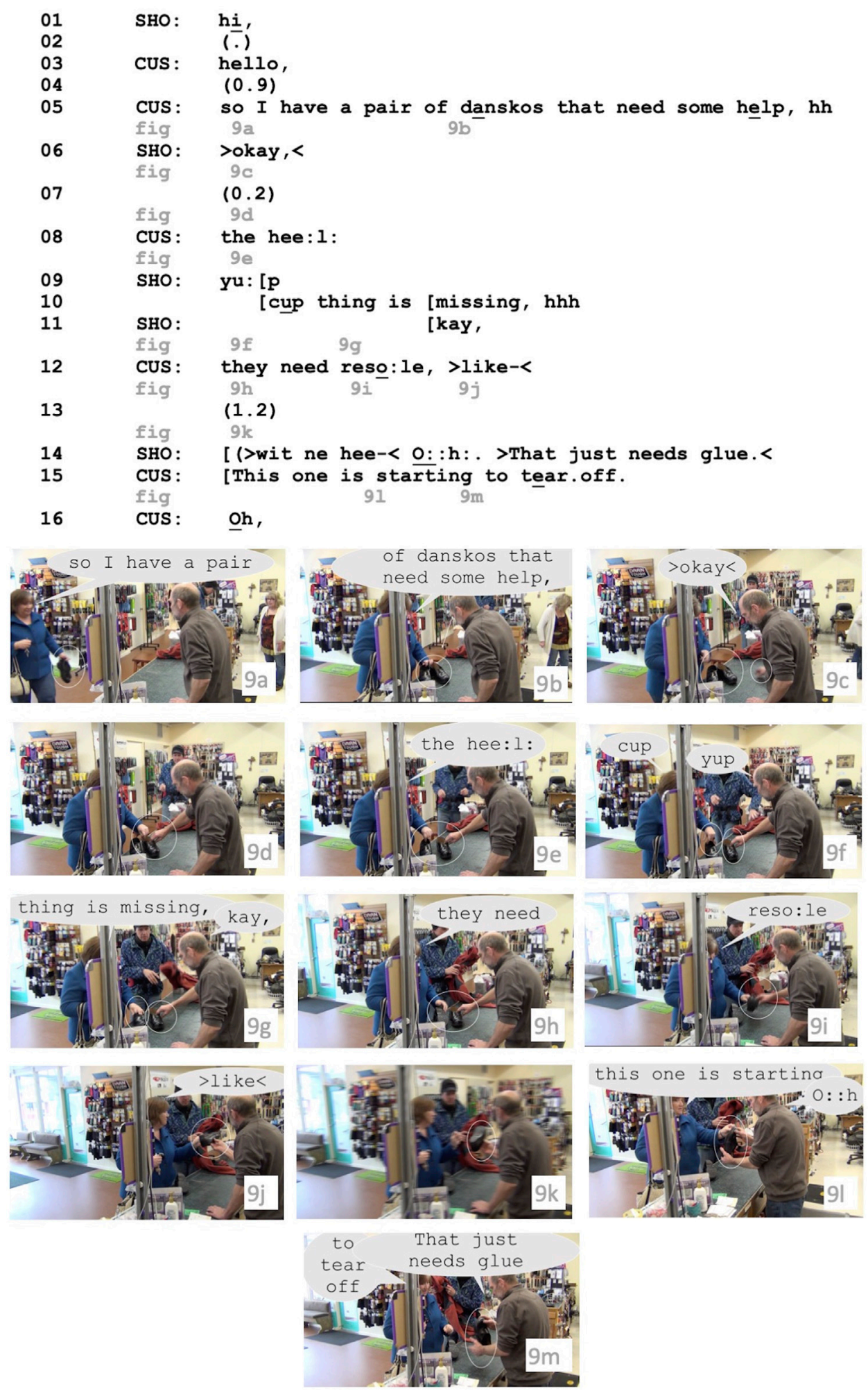

of the repair (lines 10-11), in reaction to which the shoetender halts both her verbal turn line 09 and her reach towards the shoe with her hand, which is turned instead into a point and hold, in a similar fashion to what Raymond and Lerner (2014) has described as a "suspending action", "shown to be held in abeyance rather than abandoned" (pp. 229). In other words, the shoetender here displays some indication that in retrospect her manual move towards the shoe may have been premature, but certainly not irrelevant. At the 
conclusion of nine dollars (line 11), the customer has reached another potential TRP, grammatically, prosodically and pragmatically and in orientation to this the shoetender now places her hands on the shoes directly. But again it turns out that the customer has not finished relaying the precise details of her earlier discussion with the other shoetender, in orientation to which she also holds on to the shoes; now orienting verbally to being in competition with the shoetender with respect to the turntaking, she speeds up the production of the first part of her continuation in line $11,>\left({ }^{\prime} n\right)$ probly have tuh-<, reminiscent of the abrupt-joins described by Local and Walker (2004) as being used by participants to preempt transition relevance. With her hands now firmly on the shoes, the shoetender apparently has no recourse but to wait for the customer to finalize her by now rather extended explanation of the repair of her shoes, and for this reason we now get an extremely long overlap, during which both customer and shoetender hold on to the shoes (lines 12-14). Only at the point where the customer is clearly done, as signaled by her recompleting $y^{\prime}$ know and or whatever (lines 13 and 14), does the shoetender finally pull the shoes towards her for an inspection - and even here she waits for a full second of silence (line 15) before doing so.

Extract (8) is perhaps somewhat extreme with respect to the length of the manual overlap, the period during which both shoetender and customer hold on to the shoes, but this does not distract from the fact that the underlying cause of the overlap is clearly connected to the ongoing turn-taking and turn design, and in particular to the ambiguous nature of the customer's turns-attalk in relation to projected TRPs. Moreover, the participants and in particular the shoetender - clearly demonstrate their orientation to the normative pattern of accomplishing a smooth transfer, even in such situations. The customer does so by indicating verbally that her turn was not in fact complete, and the shoetender does so by adjusting (or suspending) her manual actions as best as possible. In the end, the two together resolve the overlap by finding a place in the interaction where both agree that the transfer of the repairable item can now take place.

\section{DISCUSSION}

In this study, we hope to have demonstrated that participants in our data at the shoe shop coordinate in extremely fine detail the transfer of objects brought in for repair and the transfer of verbal turns. That is, we have argued that customers and shoetenders orient to the possible end of the requesting utterance as the appropriate locus for the manual transfer of the object. This orientation is one sense in which our data reveal a grammar-body interface, in that it shows that participants organize their embodied conduct to fit the unfolding grammatical contingencies of the requesting utterance.

The second sense in which participants in our data reveal an orientation to the grammar-body interface is through the parallel organizations of verbal and manual turn-taking. We have thus illustrated that moments of two participants holding on to the object or no participants holding on to the object in manual turntaking are frequent but brief, just as gaps and overlap are in verbal turns, and we observed similar methods for resolving the "frequent but brief" violations. The similarities in how the shoetenders and customers manage the holding and transfer of material objects in comparison with their holding and transfer of verbal turns are striking.

However, in our data there are clear cases in which manual turn-taking exhibits properties that find no parallel in verbal turn-taking. Here we explore a few of those cases and conclude that it is the affordances of some material objects which allows for different solutions to the problem of 'one person touches at a time,' while still maintaining an orientation to that norm.

For example, if the customer has brought in a pair of shoes, then if the customer and the shoetender touch the same shoe, the customer can move their hands to the other shoe. If the customer brings in a belt, then when the shoetender touches one end, the customer can move their hand to the other end, rather than removing their hand altogether. In this way, different kinds of objects afford different solutions to the practical problem of achieving "one person touches at a time."

Consider Extract (9) below, in which the customer brings in a pair of shoes. She starts the requesting sequence immediately after the greetings and before she has reached the counter; here using the preliminary statement, so I have a pair of danskos that need some help, which the shoetender receipts with okay. With this preliminary statement, she has also alerted the shoetender to the fact that both shoes will need attention. She places both shoes on the counter:

During the brief silence that follows (line 07), both participants reach for the same shoe and touch it within a few inches of one another; as we have seen repeatedly in earlier sections of the paper, overlapping hands in this way is oriented to as problematic, and at line 12 we can see that the customer has already moved her hand to the other shoe, to begin to show the problem with that shoe (the hee:l: (0.2) cup thing is missing). Thus, although there are problems with the first shoe (which the customer ends up mentioning next), because of the overlap in hands the customer shifts her hand to the second shoe and mentions the problems with that shoe first. The

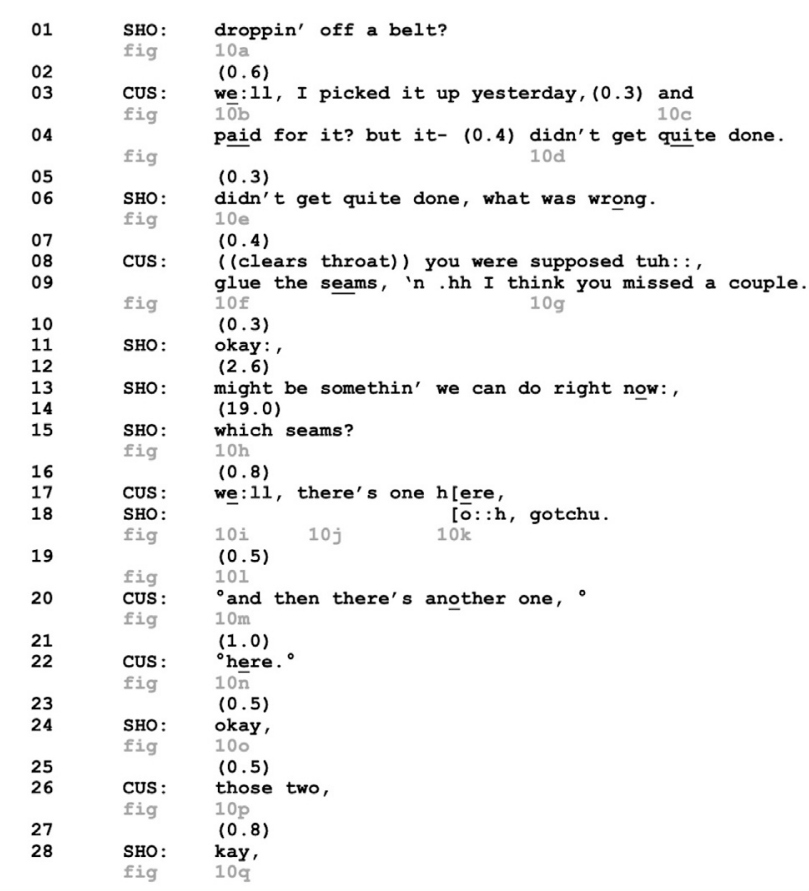



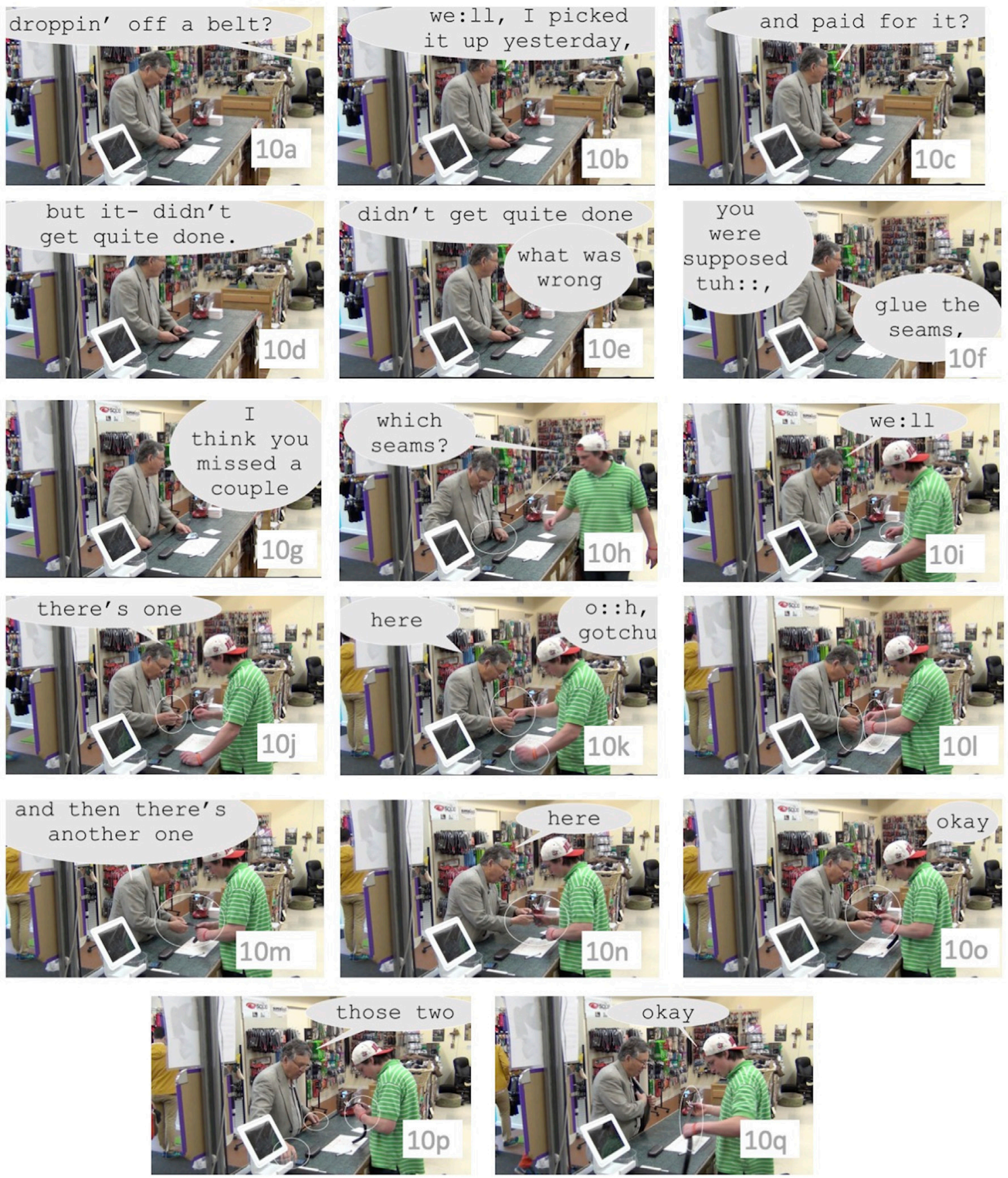

fact that she has brought in a pair of shoes makes possible this neat resolution to the overlap.

In the next extract, a customer brings in a belt, which the shop had previously repaired but not to the customer's satisfaction some seams remain unglued.

After the shoetender asks for specification about which seams are not glued properly (line 15, which seams), the customer responds by taking hold of one part of the belt, placing his fingers around it and raising it up for the shoetender to more clearly see. Even before the customer's utterance is complete, the shoetender produces a change-of- state token (line 18, oh) and a token of understanding (gotchu) and reaches for the belt. He touches the belt with the tips of his right fingers and then brings the belt closer to himself. At the same time, the customer shifts his hands to lower on the belt as he searches for the second problematic seam. He finds it and at line 22 produces here as he brings that part of the belt closer to the shoetender. The shoetender shifts his right hand to touch this new area, and the customer releases his hands from the belt.

In this extract, the length of the belt provides an affordance for both participants to touch and hold it at the same time: that is, 
they can touch or hold different parts of the belt. In this case, the shoetender holds one part of the belt while the customer searches for, and finds, the second problematic seam.

We have seen so far that particular types of objects afford different possibilities for two participants to touch or hold at the same time. Two shoes afford the possibility of one participant touching one shoe while the other participant touches the other shoe; a long belt affords the possibility of two participants touching different parts of the belt. But it is important to note here that objects and the manual stream of action in general afford possibilities of turn-taking that are simply not possible for the verbal stream.

As noted in Sacks, Schegloff and Jefferson (1974), long periods of verbal overlap are problematic for the interaction, and work is done to avoid them. One reason that long periods of overlap in the verbal stream are problematic is that they can impede hearing (although overlap does not always disrupt hearing, as Schegloff (2000) has noted); they can also introduce problems for sequence organization, in that a response made relevant by an utterance may not come in proper timing with regard to that utterance.

In the embodied and manual stream, on the other hand, long periods of holding on to the object at the same time - such as what we saw in Extract (8) - do not produce the same impediment to hearing, understanding or sequence organization. Because of the affordances of the physical stream, the verbal stream is allowed to continue as usual and although the progressivity of the larger sequence may in some cases be impeded by both participants holding on to the object, since the shoetender cannot take the object closer to their body for inspection and diagnosis - given that the customer's hands are still on the object - there is no trouble in hearing or understanding, and the immediate sequence can continue as projected. A variety of scholars, including Streeck, Goodwin and LeBaron (2011), and Mondada (2019), have commented on the affordances of the embodied and manual stream, and here we see another environment in which those affordances are put to use by participants.

At the same time, as noted above, we can see that participants in our data orient their manual actions to the unfolding grammatical organization of the turn-so-far. Shoetenders monitor the requesting utterances of the customers so as to reach for the object as the turn is coming to a place of possible grammatical completion; in this way, the shoetender orients to the norm that the customer will release hold of the item at the TRP to facilitate a no-gap, no-overlap manual transfer. That the larger social activity is one of help-needed/assistanceprovided also informs the unfolding grammatical turn and the reaching and withdrawing of hands. It is expectable in such an

\section{REFERENCES}

Beach, W. A. (1993). Transitional Regularities for 'casual' "Okay" Usages. J. Pragmatics 19, 325-352. doi:10.1016/0378-2166(93)90092-4

Davidson, J. (1984). "Subsequent Versions of Invitations, Offers, Requests, and Proposals Dealing with Potential or Actual Rejection," in Structures of Social Action. Editors J. M. Atkinson and J. Heritage (Cambridge: Cambridge University Press), 102-128.

Day, D., and Wagner, J. (2014). "Objects as Tools for Talk," in Interacting with Objects: Language, Materiality, and Social Activity. Editors M. Nevile, environment that customers will eventually relinquish hold of their objects and shoetenders will take hold of them; in the trust embodied and enmattered in the movements of the participants and the socially-built environment, the shoetenders' reaching is seen as part of their service, and not, for example, as "stealing"; similarly, the customers' withdrawal of their hands is part of a temporary offering over of their item for repair, and not, for example, as "abandonment" or "neglect". In such moments, the grammar-body interface is brilliantly revealed, as participants bring together multiple and diverse semiotic resources and webs of interpretation for constructing and making sense of joint social action.

\section{DATA AVAILABILITY STATEMENT}

Because private information is disclosed during these interactions, video data is available only upon request to the first author.

\section{ETHICS STATEMENT}

Written informed consent was not obtained from the individual(s) for the publication of any potentially identifiable images or data included in this article.

\section{AUTHOR CONTRIBUTIONS}

All authors listed have made a substantial, direct, and intellectual contribution to the work and approved it for publication.

\section{FUNDING}

This research was funded in part by a small grant from the first author's home department.

\section{ACKNOWLEDGMENTS}

We would like to thank the research assistants who gathered the data we have used here, especially Patricia Davidson. We remain deeply grateful to the owners of the shoe shop for allowing us to make these recordings and use them for research purposes.

P. Haddington, T. Heinemann, and M. Rauniomaa (Amsterdam: John Benjamins), 101-124. doi:10.1075/z.186.05day

Day, D., and Wagner, J. (2019). Objects, Bodies and Work Practice. Bristol: Multilingual Matters.

deSouza, D. K., Park, S. H., Wei, W., Zhan, K., Bolden, G. B., Hepburn, A., et al. (2021). The Gratitude Opportunity Space: The Timing of Gratitude Expressions in Object Passes. Social Interaction: Video-Based Stud. Hum. Sociality 4 (1). doi:10.7146/si.v4i1.122437

Drew, P., and Kendrick, K. H. (2018). Searching for Trouble: Recruiting Assistance through Embodied Action. Soc. Interaction: Video-Based Stud. Hum. Sociality 1 (1). doi:10.7146/si.v1i1.105496 
Ford, C. E., and Thompson, S. A. (1996). "Interactional Units in Conversation: Syntactic, Intonational, and Pragmatic Resources for the Management of Turns," in Interaction and Grammar. Editors E. Ochs, E. A. Schegloff, and S. A. Thompson (Cambridge: Cambridge University Press), 134-184. doi:10.1017/cbo9780511620874.003

Fox, B. A., and Heinemann, T. (2021). Are They Requests? an Exploration of Declaratives of Trouble in Service Encounters. Res. Lang. Soc. Interaction 54, 20-38. doi:10.1080/08351813.2020.1864154

Fox, B. A., and Heinemann, T. (2015). The Alignment of Manual and Verbal Displays in Requests for the Repair of an Object. Res. Lang. Soc. Interaction 48 (3), 342-362. doi:10.1080/08351813.2015.1058608

Fox, B., and Heinemann, T. (2017). Issues in Action Formation: Requests and the Problem with X. Open Linguistics 3, 31-64. doi:10.1515/opli-2017-0003

Fox, B., and Heinemann, T. (2016). Rethinking Format: An Examination of Requests. Lang. Soc. 45, 499-531. doi:10.1017/s0047404516000385

Fox, B., and Heinemann, T. (2020). Spatio-temporal Contingencies for Making a Request at the Shoe Repair Shop. J. Pragmatics 167, 20-67. doi:10.1016/j.pragma.2020.06.010

Fox, B., and Heinemann, T. (2019). Telescoping Responses to Requests: Unpacking Progressivity. Discourse Stud. 21 (1), 38-66. doi:10.1177/1461445618814029

Fox, B., Mondada, K., and Sorjonen, M.-L. Encounters at the Counter: Language, Embodiment and Material Objects in Shops. Cambridge: Cambridge University Press.

Heath, C., and Luff, P. (2020). "Passing Touch: Handing and Handling Tools and Implements during Surgical Procedures," in Touch, Language, and Body. Editors A. Cekaite and L. Mondada (New York: Routledge).

Heath, C., Luff, P., Sanchez-Svensson, M., and Nicholls, M. (2018). Exchanging Implements: The Micro-materialities of Multidisciplinary Work in the Operating Theatre. Sociol. Health Illn 40 (2), 297-313. doi:10.1111/1467-9566.12594

Heath, C. (2012). The Dynamics of Auction. Cambridge: Cambridge University Press. doi:10.1017/cbo9781139024020

Heinemann, T., and Fox, B. (2019). "Dropping off or Picking up? Professionals' Use of Objects as a Resource for Determining the Purpose of a Customer Encounter," in Objects, Bodies and Work Practice. Editors D. Day and J. Wagner (Bristol: Multilingual Matters), 143-163. doi:10.21832/9781788924535-009

Heritage, J. (2015). Well -prefaced Turns in English Conversation: A Conversation Analytic Perspective. J. Pragmatics 88, 88-104. doi:10.1016/ j.pragma.2015.08.008

Horlacher, A.-S. (2019). "Workplace Asymmetries and Object-Passing in Hair Salons," in Objects, Bodies and Work Practice. Editors D. Day and J. Wagner (Bristol: Multilingual Matters), 33-60. doi:10.21832/9781788924535-005

Jefferson, G. (2004). "Glossary of Transcript Symbols with an Introduction," in Conversation Analysis. Studies from the First Generation. Editor G. Lerner (Amsterdam/Philadelphia: John Benjamins), 13-31. doi:10.1075/pbns.125.02jef

Jefferson, G. (1991). "List Construction as a Task and Resource," in Interactional Competence. Editor G. Psathas (New York: Irvington Publishers), 63-92.

Jefferson, G. (1984). "Notes on Some Orderliness of Overlap Onset," in Discourse Analysis and Natural Rhetoric. Editors V. D'Urso and P. Leonardi (Padua, Italy: Cleup Editore), 11-38.

Kendon, A. (1967). Some Functions of Gaze-Direction in Social Interaction. Acta Psychologica 26, 22-63. doi:10.1016/0001-6918(67)90005-4

Kendrick, K. H. (2021). The 'Other' Side of Recruitment: Methods of Assistance in Social Interaction. J. Pragmatics 178, 68-82. doi:10.1016/j.pragma.2021.02.015

Laurier, E. (2014). The Graphic Transcript: Poaching Comic Book Grammar for Inscribing the Visual, Spatial and Temporal Aspects of Action. Geogr. Compass 8 (4), 235-248. doi:10.1111/gec3.12123

Lerner, G. H. (2004). “Collaborative Turn Sequences," in Conversation Analysis. Studies from the First Generation. Editor G. Lerner (Amsterdam/Philadelphia: John Benjamins), 225-256. doi:10.1075/pbns.125.12ler

Llewellyn, N. (2011). The Gift in Interaction: a Study of 'picking-Up the Bill'. $\mathrm{Br}$. J. Sociol. 62 (4), 718-738. doi:10.1111/j.1468-4446.2011.01388.x

Local, J., and Walker, G. (2004). Abrupt-joins as a Resource for the Production of Multi-Unit, Multi-Action Turns. J. Pragmatics 36 (8), 1375-1403. doi:10.1016/ j.pragma.2004.04.006

Local, J., and Walker, G. (2012). How Phonetic Features Project More Talk. J. Int. Phonetic Assoc. 42 (3), 255-280. doi:10.1017/s0025100312000187

Mondada, L. (2019). Participants' Orientations to Material and Sensorial Features of Objects: Looking, Touching, Smelling and Tasting while Requesting Products in Shops. Geschprächsforschung 20, 461-494.
Mondada, L., and Sorjonen, M.-L. "Embodied Trajectories of Actions in Shop Encounters: Giving or Placing Products on or over the Counter," in Encounters at the Counter. Editors B. Fox, L. Mondada, and M.-L. Sorjonen (Cambridge: Cambridge University Press).

Nevile, M., Haddington, P., Heinemann, T., and Rauniomaa, M. (2014). Interacting with Objects. Language, Materiality, and Social Activity. Amsterdam: John Benjamins.

Ogden, R. (2013). Clicks and Percussives in English Conversation. J. Int. Phonetic Assoc. 43 (3), 299-320. doi:10.1017/s0025100313000224

Rauniomaa, M., and Keisanen, T. (2012). Two Multimodal Formats for Responding to Requests. J. Pragmatics 44 (6-7), 829-842. doi:10.1016/ j.pragma.2012.03.003

Raymond, G., and Lerner, G. H. (2014). “A Body and its Involvements,” in Multiactivity in Social Interaction: Beyond Multitasking. Editors P. Haddington, T. Keisanen, L. Mondada, and M. Nevile (Amsterdam: John Benjamins), 227-246. doi:10.1075/z.187.08ray

Sacks, H., Schegloff, E. A., and Jefferson, G. (1974). A Simplest Systematics for the Organization of Turn-Taking for Conversation. Language 50 (4), 696-735. doi:10.1353/lan.1974.0010

Sanchez Svensson, M., Heath, C., and Luff, P. (2007). "Instrumental Action: The Timely Exchange of Implements during Surgical Operations," in Proceedings of the 10th European Conference on Computer Supported Cooperative Work, Limerick, Ireland, September 24-28, 2007. Editors L. J. Bannon, I. Wagner, R. H. R. Harper, and K. Schmidt (Berlin: Springer), 41-60.

Schegloff, E. A. (2000). Overlapping Talk and the Organization of Turn-Taking for Conversation. Lang. Soc. 29 (1), 1-63. doi:10.1017/s0047404500001019

Sorjonen, M.-L., and Raevaara, L. (2014). “On the Grammatical Form of Requests at the Convenience Store," in Requesting in Social Interaction. Editors P. Drew and E. Couper-Kuhlen (Amsterdam: John Benjamins), 243-268. doi:10.1075/ slsi.26.10sor

Stivers, T., and Rossano, F. (2010). Mobilizing Response. Res. Lang. Soc. Interaction 43 (1), 3-31. doi:10.1080/08351810903471258

Streeck, J., Goodwin, C., and LeBaron, C. (2011). "Embodied Interaction in the Material World: An Introduction," in Embodied Interaction: Language and the Body in the Material World. Editors J. Streeck, C. Goodwin, and C. LeBaron (Cambridge: Cambridge University Press), 1-26.

Streeck, J. (1996). How to Do Things with Things. Hum. Stud. 19 (4), 365-384. doi:10.1007/bf00188849

Tuncer, S., and Haddington, P. (2020). Object Transfers: An Embodied Resource to Progress Joint Activities and Build Relative agency. Lang. Soc. 49, 61-87. doi:10.1017/s004740451900071x

Wootton, A. J. (1991). “Obtaining an Object from a Young Child: the Social Organization of a Set of Practices," in Sociological Studies of Child Development, Vol. 4: Perspectives on and of Children. Editor S. E. Cahill (London: JAI Press), 155-179.

Wootton, A. J. (1997). Interaction and the Development of Mind. Cambridge: Cambridge University Press. doi:10.1017/cbo9780511519895

Wootton, A. J. (1994). Object Transfer, Intersubjectivity and Third Position Repair: Early Developmental Observations of One Child. J. Child. Lang. 21 (3), 543-564. doi:10.1017/s0305000900009454

Conflict of Interest: The authors declare that the research was conducted in the absence of any commercial or financial relationships that could be construed as a potential conflict of interest.

Publisher's Note: All claims expressed in this article are solely those of the authors and do not necessarily represent those of their affiliated organizations, or those of the publisher, the editors and the reviewers. Any product that may be evaluated in this article, or claim that may be made by its manufacturer, is not guaranteed or endorsed by the publisher.

Copyright (c) 2021 Fox and Heinemann. This is an open-access article distributed under the terms of the Creative Commons Attribution License (CC BY). The use, distribution or reproduction in other forums is permitted, provided the original author(s) and the copyright owner(s) are credited and that the original publication in this journal is cited, in accordance with accepted academic practice. No use, distribution or reproduction is permitted which does not comply with these terms. 